Paul Srodecki

\title{
Bollwerk gegen Ost und West - Das Bild eines restituierten polnischen Staates in den Überlegungen polnischer Publizisten vor dem Hintergrund des Ersten Weltkrieges
}

Der Erste Weltkrieg führte wie kaum ein anderer Konflikt zuvor zu weitreichenden Veränderungen auf der politischen Karte Europas. Der Zusammenbruch der Mittelmächte im November 1918 und die Friedenskonferenz von Paris mit dem anschließenden Vertrag von Versailles 1919 hatten - auf den Ruinen des Deutschen Kaiserreichs, Österreich-Ungarns und des Russländischen Imperiums - die Entstehung zahlreicher neuer Staaten im östlichen Mitteleuropa, dem Baltikum und Südosteuropa zur Folge. Der größte und seiner regionalpolitischen Bedeutung nach wichtigste dieser Staaten war zweifelsohne Polen, das nach 123 Jahren wieder seine Unabhängigkeit erringen konnte. Bereits im Vorfeld von Versailles und noch während der Kampfhandlungen an der West- und Ostfront haben sich zahlreiche polnische Publizisten und Unabhängigkeitsaktivisten mit großem Eifer für die polnische Sache eingesetzt. Der folgende Beitrag untersucht das Bild, das die polnische Publizistik während des Ersten Weltkrieges wie auch in den Jahren unmittelbar danach von einem restituierten polnischen Staat zeichnete. Bei der Beantwortung der Frage nach der außenpolitischen Ausrichtung dieser neugegründeten Rzeczpospolita in den Überlegungen der polnischen Eliten soll allem voran der in Polen seit dem späten Mittelalter und der Frühen Neuzeit weit verbreitete Bollwerkstopos stehen. ${ }^{1}$

\footnotetext{
1 Zu ostmitteleuropäischen Bollwerksdiskursen vgl. Srodecki, Paul: Antemurale Christianitatis. Zur Genese der Bollwerksrhetorik im östlichen Mitteleuropa an der Schwelle vom Mittelalter zur Frühen Neuzeit, Husum 2015; ders.: Antemurale-based frontier identities in East Central Europe and their ideological roots in medieval/early modern alterity and alienity discourses, in: Collective Identity in the Context of Medieval Studies, hrsg. von M. Antonín Malaníková/ R. Antonín, Ostrava 2016, S. 97-120.
} 


\section{Zwischen Messianismus und Antemurale}

Um das Selbstverständnis der polnischen Unabhängigkeitsaktivisten des frühen 20. Jahrhunderts wie auch ihre geopolitische Einordnung eines restituierten polnischen Staates (vor allem im Verhältnis zu Russland) verstehen zu können, kommt man nicht umher, sich mit den bereits im 19. Jahrhundert formulierten Konzepten der polnischen Eliten zu befassen. Polen als eine Scheidelinie zwischen der westlichen Welt der (west)europäischen Zivilisation und der östlichen Despotie Asiens war ein Bild, das der politische Schriftsteller und Publizist Stanisław Staszic fast schon programmatisch für das gesamte 19. und 20. Jahrhundert skizzierte, als er - in Anlehnung an spätmittelalterlich-frühneuzeitliche Bollwerkstopoi und das säkularisierte Europakonzept der polnischen Aufklärer des 18. Jahrhunderts - im Jahre 1807 konstatierte:

»Durch Polen verläuft diese sich vom Schwarzen Meer bis zur Ostsee ziehende [Trenn-] Linie, die Europa vor Asien verschließt. In Polen liegt die Vormauer Europas gegen die Anstürme aus Asien. Zwischen Dnjepr und Bug, zwischen Weichsel und Oder befinden sich die Gräber, die die Horden verschlangen, welche von Asien aus zur Unterbindung und Zerstörung der europäischen Zivilisation losgezogen waren. $\Perp^{2}$

Die misslungenen und rigoros niedergeschlagenen Aufstände 1830-31 und 1863 - 64 der Polen gegen St. Petersburg wie auch die darauffolgenden russischen Repressalien und Deportationen wirkten nachhaltig auf das Selbstverständnis der polnischen Eliten, die für die Unabhängigkeit kämpften. Noch aus der Zeit der frühneuzeitlichen Rzeczpospolita wohl bekannt, dienten die antirussischen Topoi - der Moskowiter bzw. Russen als grausame und asiatisch-barbarische »inimici Europae» wie auch der Polens als Bollwerk gegen die »schismatischen russischen Horden« - den polnischen Unabhängigkeitsaktivisten des 19. Jahrhunderts als

2 Staszic, Stanisław: O statystyce Polski krótki rzut wiadomości. Potrzebnych tym, którzy ten kray chca oswobodzić, i tym którzy w nim chca rządzić [Eine kleine Auswahl an Informationen zur Statistik Polens. Nützlich denen, die das Land befreièn und denen, die es regieren wollen], Warszawa 1807, S. 32 f.: „W Polsce iest ta linia między morzém Czarnem i między morzém Baltyckiém, która Europę od Azyi zamyka. W Polsce iest przedmurze Europy przeciw nawałom z Azyi. Między Dnieprem i Bugiem, Wisła i Odra, znayduia się groby, które pochłonęły wszystkie hordy, co z Azyi wychodziły, na wstrzymanie i na burzenie cywilizacyi Europy.»Vgl. Lawaty, Andreas: Polen und Europa in der Aufklärung, in: Europas Platz in Polen. Polnische Europa-Konzeptionen vom Mittelalter bis zum EU-Beitritt (Einzelveröffentlichungen des Deutschen Historischen Instituts Warschau, Bd. 11), hrsg. von Claudia Kraft/ Katrin Steffen, Osnabrück 2007, S. 105-130, hier S. 120. Zum Staats- und Reformgedanken bei Staszic siehe Topolski, Jerzy: LıÉtat dans la pensée politique de Stanislav Staszic, in: LıÉtat dans les doctrines économiques et politiques de la Renaissance à nos jours. Colloque des 24-26 mai 1988, Université des Sciences humaines de Strasbourg, Strasbourg 1990, S. 99-100; Daszyńska, J.: Przestrogi dla Polski i Anglii w pismach Stanisława Staszica i Benjamina Franklina [Mahnungen an Polen und England in den Schriften des Stanisław Staszic und Benjamin Franklin], in: Oświeceni wobec rozbiorów Polski [Die Aufklärer gegenüber den Teilungen Polens], hrsg. von Jerzy Grobis, Łódź 1998, S. 215 - 227; Nosov, B.: Stanisław Staszic ostatnia przestroga dla Polski [Stanisław Staszic - die letzte Mahnung an Polen], in: Napis. Pismo poświęcone literaturze okolicznościowej i użytkowej 6 (2000), S. 239-243. 
willkommene Argumentationsgrundlagen gegen das Russländische Kaiserreich als einer der Teilungsmächte eines seit 1795 von der politischen Landkarte Europas verschwundenen polnischen Staates. Auch angesichts einer zunehmenden Säkularisierung der polnischen Vormauervorstellung im 19. Jahrhundert wurde nun zunehmend die geopolitische Bedeutung Polens für den europäischen Westen bemüht. Den nationalpolnischen Publizisten galt Polen fortan als der hart umkämpfte Vorposten der von der Aufklärung geprägten und auf liberalen Grundwerten aufgebauten westlichen Zivilisation gegen das östliche Barbarentum des autokratischen Russlands. ${ }^{3}$ Dieser Rückgriff auf ältere Vormauervorstellungen verhalf überdies den auf eine innere Konsolidierung angelegten In- und Exklusionsstrategien zur Herausbildung eines polnisch-nationalen Denkens und löste eine Renaissance des Bollwerksbegriffs aus. ${ }^{4}$ Alte Muster aus der Jagiellonenzeit und der frühneuzeitlichen Rzeczpospolita dienten bei dieser verweltlichten Form der Bollwerksallegorie als willkommene Vorlagen. ${ }^{5}$

Großen Anteil hatte daran auch die polnische Diaspora, die das Bild des polnischen Messianismus, dessen Wurzeln ein Teil der heutigen polnischen Geschichtswissenschaft in der "sarmatischen« Ideologie der Rzeczpospolita sehen will, ${ }^{6}$ euro-

3 Rzońca, Jan: Polacy i Rosjanie - wzajemne opinie w pracach historycznych i publicystycznych [Polen und Russen - Gegenseitige Wahrnehmungen in historischen und publizistischen Arbeiten], in: Swoi i obcy [Eigene und Fremde] (Kultura polityczna w Polsce, Bd. 4,1), Bd. 1, hrsg. von Marceli Kosman, Poznań 2004, S. 137-160, hier S. 141 ff.; Janowski, Maciej: Polen im 19. Jahrhundert. Europa an der Weichsel?, in: Europas Platz in Polen. Polnische Europa-Konzeptionen vom Mittelalter bis zum EU-Beitritt (Einzelveröffentlichungen des Deutschen Historischen Instituts Warschau, Bd. 11), hrsg. von Claudia Kraft/ Katrin Steffen, Osnabrück 2007, S. 131-155, hier S. 131; Lawaty, Andreas: Polen und Europa in der Aufklärung, in: Europas Platz in Polen. Polnische Europa-Konzeptionen vom Mittelalter bis zum EU-Beitritt (Einzelveröffentlichungen des Deutschen Historischen Instituts Warschau, Bd. 11), hrsg. von Claudia Kraft/ Katrin Steffen, Osnabrück 2007, S. 105 - 130, hier S. 118-121.

4 Tazbir, Janusz: Polska przedmurzem Europy [Polen als Vormauer Europas], Warszawa 2004, S. $135-159$.

5 Rzońca, Polacy i Rosjanie, S. 141 ff.; Janowski, Polen im 19. Jahrhundert, S. 131; Lawaty, Polen und Europa, S. $118-121$.

$6 \mathrm{Zu}$ dieser unter den Geschichts-, Literatur- und Kulturwissenschaftlern umstrittenen These siehe Jabłońska-Deptuła, E./ Skarbek, J.: W dobie między powstaniami (1832 - 1864) [Zwischen den Aufständen (1832 - 1864)], in: Chrześcijaństwo w Polsce. Zarys przemian 966-1979 [Das Christentum in Polen. Eine Skizze des Wandels 966-1979] (Biblioteka historii społeczno-religijnej Instytutu Geografii Historycznej Kościoła w Polsce, Bd. 7), hrsg. von J. Kłoczowski, Lublin ${ }^{2}$ 1992, S. 403 - 455, hier: S. 403 - 410; Obremski, K.; Sarmacki mesjanizm [Sarmatischer Messianismus], in: Ogród 7 (1994), S. 119-130; ders.: Jan III - od Wiednia do Jerozolimy (apogeum sarmackiego mesjanizmu) [Jan III. - von Wien nach Jerusalem (der Höhepunkt des sarmatischen Messianismus)], in: Między barokiem a oświeceniem. Apogeum sarmatyzmu. Kultura polska drugiej połowy XVII wieku [Zwischen Barock und Aufklärung. Der Höhepunkt des Sarmatismus. Die polnische Kultur in der zweiten Hälfte des 17. Jahrhunderts], hrsg. von K. Stasiewicz/ S. Achremczyk, Olsztyn 1997, S. 100 - 109; ders.: „Wielka teraźniejszość» i alegoreza jako konteksty sarmackiego mesjanizmu. [„Die große Gegenwart" und die Allegorese als Kontexte des sarmatischen Messianismus], in: Barok 11,1 (2004), S. 105 -118; J. Garewicz, Sarmatyzm i mesjanizm. Tezy do diskusji [Sarmatismus und Messianismus. Thesen zur Diskussion], in: August Cieszkowski (1814-1894). W setną rocznicę śmierci [August Cieszkowski (1814-1894). Zum hundertsten Todestag], hrsg. von B. Markiewicz/S. Pieróg, Warszawa 1996, S. 11-15; Niedźwiedź, J.: Mesjanizm [Der Messianismus], in: Słownik sarmatyzmu. Idee, pojęcia, symbole [Wörterbuch des Sarmatismus. Ideen, Begriffe, Symbole], hrsg. von A. Borowski, Kraków 2001, S. 111-114; Olschowsky, H., Sarmatismus, Messianismus, Exil, Freiheit - 
paweit verbreitete. ${ }^{7}$ Am deutlichsten zeigte sich die von den polnischen Messianisten Polen zugeschriebene Märtyrer-Rolle in der bis heute in Polen populären Parole »Polska Chrystusem narodów» (»Polen, Christus der Völker«), zu deren wohl berühmtesten Propagatoren der Dichter Adam Mickiewicz als wichtigster Vertreter der polnischen Romantik zählte. ${ }^{8}$ Vor dem Hintergrund der polnischen RomantikBewegung entstand auch der sogenannte "Winkelriedismus», der in dem Heldenkult um die mythische Figur des im aufopferungsvollen Kampf gegen die Habsburger gefallenen Eidgenossenen Arnold Winkelried Parallelen zur historischen Rolle Polens sah. ${ }^{9}$ Der zweite große Dichter der polnischen Romantik, Juliusz Słowacki, ließ den Titelhelden seines 1833 verfassten Gedichts »Kordian« - gewissermaßen als polemische Antwort auf Adam Mickiewicz und die Messianisten - den in Polen ebenfalls bis heute weit verbreiteten Ausspruch sagen: „Polen, Winkelried der Völ-

typisch polnisch?, in: A. Lawaty/H. Orłowski (Hgg.), Deutsche und Polen. Geschichte, Kultur, Politik, hrsg. von Andreas Lawaty/Hubert Orłowski, München ${ }^{2} 2006$, S. $279-287$.

7 Pluskiewicz, E.: Mesjanizm w myśli polskiej pierwszej połowy XIX wieku [Der Messianismus im polnischen Denken der ersten Hälfte des 19. Jahrhunderts], in: Zeszyty Naukowe Politechniki Śląskiej 748 (1983), S. 105-115; Salamon, J.: Mesjanizm polski XIX wieku na tle historycznych uwarunkowań [Der polnische Messianismus des 19. Jahrhundert vor dem Hintergrund historischer Rahmenbedingungen], in: Zeszyty Naukowe Uniwersytetu Jagiellońskiego. Studia Religiologica 23 (1990), S. 49 - 69; Ziółek, Jan: „Wskrzesić Polskę, zbawić świat». Drogi polityczne polskich emigrantów [»Polen wiederbeleben, die Welt erlösen«. Die politische Wege polnischer Emigranten], in: Polskie powstania narodowe na tle przemian europejskich w XIX wieku [Die polnischen Nationalaufstände vor dem Hintergrund der europaweiten Veränderungen im 19. Jahrhundert] (Z'ródła i monografie, 215), hrsg. von Anna Barańska/ Witold Matwiejczyk/ Jan Ziółek, Lublin 2001, S. 155 - 166.

8 Dopart, Boguslaw: Polska - Chrystusem narodów? [Polen - Christus der Völker?], in: „Dziady“ Adama Mickiewicza. Poemat, adaptacje, tradycje [Die »Totenfeier« des Adam Mickiewicz. Poemat, Adaptionen, Traditionen], hrsg. von dems., Kraków 1999, S. 70 - 92; Landgrebe, Alix: „Wenn es Polen nicht gäbe, dann müsste es erfunden werden«. Die Entwicklung des polnischen Nationalbewusstseins im europäischen Kontext von 1830 bis in die 1880er Jahre (Studien der Forschungsstelle Ostmitteleuropa an der Universität Dortmund, Bd. 35), Wiesbaden 2003, S. 74-85 u. 166-177; Szymanis, Eligiusz: Mistyczny wymiar Mickiewiczowskiego mesjanizmu [Die mystische Seite des Mickiewicz-Messianismus], in: Mickiewicz mistyczny [Der mystische Mickiewicz], hrsg. von Andrzej Fabianowski/ Ewa Hoffmann-Piotrowska, Warszawa 2005, S. 177-191; Szymani, Ewa: Romantische Religiosität in Polen am Beispiel ausgewählter Texte von Adam Mickiewicz, in: Deutsche und Polen in der Aufklärung und in der Romantik. Verweigerung des Transfers? (Studien zum deutsch-polnischen Kulturtransfer, Bd. 2), hrsg. von ders., Leipzig 2011, S. 161-193. Zur weiteren Verbreitung des polnischen Messianismus unter den polnischen geistigen Eliten des 19. und frühen 20 Jhs. siehe Goszczyńska, J.: Mesjanizm w polskiej i słowackiej literaturze romantycznej (próba konfrontacji) [Der Messianismus in der polnischen und slowakischen Literatur der Romantik (der Versuch einer Konfrontation)], in: Polono-Hungarica. Nyelvészet, irodalom, történelem [Polono-Hungarica. Linguistik, Geschichte, Literatur], hrsg. von J. Bańczerowski/ J. Snopek, Budapest 1992, S. 143-148; Prussak, Maria: "Po ogniu szum wiatru cichego». Wyspiański i mesjanizm ["Nach dem Feuer das Rauschen eines stillen Windes«. Wyspiański und der Messianismus], Warszawa 1993; Jaworski, Wit: Eleuteryzm i mesjanizm. U źródeł filozofii społecznej Wincentego Lutosławskiego [Eleutherismus und Messianismus. Zu den Ursprüngen der Gesellschaftsphilosophie des Wincenty Lutosławski], Kraków 1994; Krasicki, J.: Eschatologia i mesjanizm. Studium światopoglądu Mariana Zdziechowskiego [Eschatologie und Messianismus. Eine Studie zur Weltanschauung des Marian Zdziechowski], Wrocław 1994.

9 Im Gegensatz zum polnischen Messianismus, der die »Märtyrer«-Rolle Polens als gottgegeben ansah, propagierten die »Winkelriedisten« eine aktive Beteiligung an der Widerstandsbewegung gegen die Teilungsmächte und riefen wiederholt zur militärischen Gegenwehr auf. Vgl. Kaczyńska, Leokadia: Winkelried ożył? Teatralne odczytywanie »Kordiana» (1945-2000) [Die Wiedergeburt des Winkelried? Teatralische Wiedergabe des »Kordian" (1945-2000)], Gdańsk 2006; Piechota, Marek (Hrsg.): Słownik literatury polskiej [Wörterbuch polnischer Literatur], Katowice 2008. 
ker!« (»Polska Winkelriedem narodów!«)10 Auch Zygmunt Krasiński, als der Dritte in dem sogenannten "Dreigestirn der polnischen Romantik» (poln. "Trójca wieszczów «) ${ }^{11}$, verband in seinen Werken den polnischen Messianismus mit dem erprobten Bollwerksmotiv. ${ }^{12}$

An den Messianismus der polnischen Romantik knüpfte ${ }^{13}$ - im gewissen Sinne als Ergebnis einer zunehmenden Slawophilie - in besonderem Maße auch die von den politischen Eliten im 19. und frühen 20. Jahrhundert gern propagierte Überzeugung an, Polen sei stets auch ein aufopferungsbereites »antemurale» des Slawentums gegen die aggressive Germanisierung aus dem Westen gewesen. Zu den berühmtesten Verfechtern dieses Bildes zählte zweifelsohne der politische Aktivist und spätere Gründer der nationalkonservativen Bewegung »Narodowa Demokracja» (ND oder, nach den beiden Anfangsbuchstaben, auch "Endecja»), Roman Dmowski, der in seiner 1908 erschienenen Schrift "Niemcy, Rosya i kwestya polska» (»Deutschland, Russland und die polnische Frage») in Polen das Hauptbollwerk des Slawentums gegen Deutschlands "Drang nach Osten« sah ${ }^{14}$ und dem-

10 Inglot, Mieczysław: „Kordian« Juliusza Słowackiego [Der „Kordian« des Juliusz Słowacki], Warszawa 1993, S. 20, 25 f., 31 u. 48. Vgl. Makowski, Stanislaw; Juliusz Słowacki (Biblioteka ^Polonistyki`), Warszawa 1980 , S. $248-253$.

11 Langer, Dietger: Grundzüge der polnischen Literaturgeschichte (Grundzüge, Bd. 26), Darmstadt 1975, S. 85; Zawodniak, Mariusz: "Reakcyjny kanon«, czyli trójca wieszczów w klasowej wizji romantyzmu (kartka z dziejów recepcji) ["Ein reaktionärer Kanon«, also das Dreigestirn der polnischen Romantik in der klassischen Vision der Romantik], in: Mickiewicz, Słowacki, Krasiński. Romantyczne uwarunkowania i współczesne konteksty [Mickiewicz, Słowacki, Krasiński. Romantische Rahmenbedingungen und zeitgenössiche Kontexte], hrsg. von Ewa Owczarz/ Jerzy Smulski, Łowicz 2001, S. 61- 70.

12 Vgl. Fiećko, J.: Despotyzm, anarchizm i przedmurze chrześcijańskiej Europy. Memoriał Zygmunta Krasińskiego do François Guizota (z grudnia 1846 r.) [Despotismus, Anarchismus und die Vormauer des christlichen Europas. Zygmunt Krasińskis Memorandum an François Guizot (vom Dezember 1846)], in: Swoi i obcy. Studia z dziejów myśli Wielkiej Emigracji [Die Eigenen und die Fremden. Studien zur Ideengeschichte der Großen Emigration] (Publikacje Instytutu Historii UAM, Bd. 47), hrsg. von Przemysław Matusik/ K. Marchlewicz, Poznań 2004, S. 81-90. Eine besondere Rolle bei der Erhaltung der nationalen Identität in Zeiten staatlicher Inexistenz schrieben die polnischen Romantiker der Volksdichtung zu, die als wichtiger Orientierungsanker auch den »unteren« Bevölkerungsschichten ein nationales Zusammengehörigkeitsgefühl vermitteln sollte. Siehe hierzu Simonides, Dorota: Der Einfluss der Brüder Grimm auf die Sammlung und Erforschung der slawischen Volksdichtung, in: Erzählkultur. Beiträge zur kulturwissenschaftlichen Erzählforschung. Hans-Jörg Uther zum 65. Geburtstag, hrsg. von Rolf Wilhelm Brednich, Berlin/ New York 2009, S. 133 - 144, hier S. $138 \mathrm{ff}$.

$13 \mathrm{Zu}$ den Verbindungen zwischen dem polnischen Messianismus und dem Panslawismus siehe Pakciński, M.: Mesjanizm i słowianofilstwo w myśli Mariana Zdziechowskiego [Messianismus und Slawophilie im Denken des Marian Zdziechowski], in: Przeglad Humanistyczny 33,2 (1989), S. 65 - 79; Goszczyńska, Joanna, Mesjanizacja idei słowianofilskich w poezji Sama Bohdana Hrobonia [Die Messianisierung der slawophilen Ideen in der Poesie des Samuel Bohdan Hroboň], in: Wielkie tematy kultury w literaturach słowiańskich [Die großen Kulturthemen in den slawischen Literaturen], Bd. 5 (Slavica Wratislaviensia, Bd. 128; Acta Universitatis Wratislaviensis, Bd. 2665), hrsg. von Izabella Malej/ Z. Tarajło-Lipowska Wrocław 2004, S. 32 - 39; Krzoska, M.: Historische Mission und Pragmatismus. Die slawische Idee in Polen im 20. Jahrhundert, in: Osteuropa 59,12 (2009), S. 77-94.

14 Dmowski, R.: Niemcy, Rosya i kwestya polska [Deutschland, Russland und die polnische Frage], Lwów 1908. Vgl. Bułhak, Władysław: Dmowski - Rosja a kwestia Polska. U źródeł orientacji rosyjskiej obozu narodowego 1886-1908 [Dmowski - Russland und die polnische Frage. Zu den Ursprüngen der Russlandanlehnung des nationalen Lagers 1886-1908], Warszawa 2000; J. Tazbir, Polska przedmurzem Europy, S. 176 u. 183. Die Vorstellung eines "slawischen Bollwerks" gegen ein als feindlich eingestuftes deutschsprachiges "Germanentum" findet sich zur etwa selben Zeit auch in anderen slawisch-germanischen Grenzregionen, so etwa bei den Slowenen. Siehe hierzu Rumpler, Helmut:, Zwischen allen Fron- 
entsprechend die polnischen Gebietsansprüche gegenüber Deutschland formulierte. ${ }^{15}$ Allem voran Großpolen mit seinen Zentren Posen und (im geringeren Maße) Gnesen wurde von den polnischen Panslawisten die Rolle eines "festen Bollwerks polnischen Denkens» gegen den preußischen Staat zugeschrieben. ${ }^{16}$ Während aber etwa von Roman Dmowski zeit seines Lebens den Russen die Führungsrolle innerhalb der slawischen Völker zugedacht worden war, wurde von der Mehrheit der polnischen Historiographie und politischen Publizistik Russland, das in eine mongolisch-asiatische Tradition gestellt wurde, die Zugehörigkeit zur slawischen Welt verwehrt. ${ }^{17}$ So hatte bereits 1843 der Historiker Jędrzej Moraczewski mit einem gewissen Pathos konstatiert, Polens ambivalente Mission "im Kreis der zivilisierten Völker" sei schon immer einerseits die Verteidigung der slawischen Welt gegen den Westen, andererseits die Abwehr Europas vor dem barbarischen Asien gewesen. ${ }^{18}$ Im späten 19. und frühen 20. Jahrhundert entstand so unter den polnischen Historikern, Schriftstellern, Theologen und politischen Publizisten wie Adam Pajgert, Adam Szelągowski, Stanisław Zakrzewski oder Oskar Halecki ein über ideologische und politische Grenzen hinweg weit ver-

ten. Die Wiener Regierung und die nationalpolitischen Hoffnungen der Slowenen vor 1914, in: Nation, Nationalitäten und Nationalismus im östlichen Europa. Festschrift für Arnold Suppan zum 65. Geburtstag, hrsg. von Marija Wakounig/ Wolfgang Mueller/ Michael Portmann, Wien/ Berlin/ Münster 2010, S. $279-296$, hier S. 285.

15 Gehrke, Roland: Der polnische Westgedanke bis zur Wiedererrichtung des polnischen Staates nach Ende des Ersten Weltkrieges. Genese und Begründung polnischer Gebietsansprüche gegenüber Deutschland im Zeitalter des Nationalismus (Materialien und Studien zur Ostmitteleuropa-Forschung, Bd. 8), Marburg 2001, S. $258-267$.

16 Molik, Witold: Wurde Großpolen im 19. und zu Beginn des 20. Jahrhunderts borussifiziert? In: Deutschlands östliche Nachbarschaften. Eine Sammlung von historischen Essays für Hans Henning Hahn (Die Deutschen und das östliche Europa. Studien und Quellen, Bd. 4), hrsg. von Edmund Dmitrów/ Tobias Weger, Frankfurt a. M. 2009, S. 391-410, hier S. 396 u. 407.

17 Mikołajczak, A. W.: Łacińska tożsamość Słowianszczyzny [Die lateinische Identität des Slawentums], in: Idee wspólnotowe słowiańszczyzny [Unionsgedanken im Slawentum], hrsg. von A. Wikolajczak/ W. Szulc/ B. Zieliński, Poznań 2004, S. 9-16; J. Rzońca, Polacy i Rosjanie, S. 141 ff.; Wądołowski, Wojciech: Portret Moskala w »Rosji, Europie i Polsce« Henryka Kamieńskiego (1857 r.) [Das Porträt des Moskowiters in dem Werk "Russland, Europa und Polen» des Henryk Kamieński], in: Bizancjum, prawosławie, romantyzm. Tradycja wschodnia w kulturze XIX wieku [Byzanz, das orthodoxe Christentum und die Romantik. Östliche Traditionen in der Kultur des 19. Jahrhunderts] (Antyk Romantyków), hrsg. von Jarosław Ławski/ Krzysztof Korotkich, Białystok 2004, S. 75-82.

18 Moraczewski, J.: Dzieje Rzeczypospolitéj Polskiéj do piętnastego wieku [Die Geschichte der polnischen Rzeczpospolita bis zum 15. Jahrhundert], Poznań 1843, S. 196: „Posłannictwem Polski w gronie narodów cywilizowanych były: obrona życia słowiańskiego przeciw oswieceńszemu zachodowi, obrona Europy przeciw barbarzyńskiéj Azyi, a nokoniec szerzenie chrześcijaństwa jako postęp na Pomorzu, Litwie. Mimo słobość zewnętrzna, Polska nie zaspała obowiązków i odpowiedziała przeznaczeniu swemu." [»Polens Missionen im Kreis der zivilisierten Völker waren: die Verteidigung des slawischen Lebens vor dem aufgeklärteren Westen, die Verteidigung Europas vor dem barbarischen Asien und schließlich die Ausbreitung des Christentums im Zeichen des Fortschritts in Pommern und Litauen. Ungeachtet der inneren Schwäche hat Polen diese Pflichten nicht sverschlafen und gab Antwort seiner Bestimmung. «] Vgl. Morawiec, Malgorzata: Antemurale christianitatis. Polen als Vormauer des christlichen Europa, in: Jahrbuch für Europäische Geschichte 2 (2001), S. 249 - 260, hier S. 258; Tazbir, Polska przedmurzem Europy, S. 142, die beide fälschlicherweise das Jahr 1851 als Entstehungsdatum des Zitats angeben. 
breiteter Diskurs zum polnischen antemurale-Selbstverständnis und seinen geschichtlichen Wurzeln. ${ }^{19}$

\section{Bollwerk gegen Deutschland und Russland}

Der Ausbruch des Ersten Weltkrieges eröffnete den polnischen Unabhängigkeitsaktivisten neue Möglichkeiten. Hatten allem voran die Teilungsmächte noch vor 1914 die polnische Frage mit größter Achtsamkeit behandelt und mit der Bewahrung des Status Quo und der entschiedenen Bekämpfung jeglicher Unabhängigkeitsbestrebungen verbunden, ${ }^{20}$ so bildeten schon kurz nach Kriegsbeginn die Polen selbst ein jetzt eifrig umworbenes Ziel der jeweiligen Kriegsparteien; »über Nacht" seien sie »lieb Kind bei allen kriegführenden Nationen geworden", wie die „Neue Zürcher Zeitung» bereits am 8. August 1914 kommentierte. ${ }^{21}$ Sowohl die Mittelmächte als auch die Triple Entente versuchten in der Folge, die polnische Frage für eigene Zwecke zu instrumentalisieren. Am weitesten waren in den ersten Kriegsjahren wohl die Polenpläne ersterer vorangeschritten: Ein restituierter, allerdings vor allem außenpolitisch weitgehend von Deutschland und ÖsterreichUngarn abhängiger polnischer Staat sollte den Platz eines wichtigen Pufferstaats gegen Russland einnehmen, die wehrfähigen Polen aus den besetzten Gebieten im Osten zu ihren bereits im Deutschen Heer beziehungsweise in den k.u.k. Streitkräften der sogenannten Gemeinsamen Armee kämpfenden Landsleute dazustoßen und in einer neu zu schaffenden polnischen Armee die Mittelmächte in ihrem Kampf gegen die Entente unterstützen. Hierzu wurde unter anderem im November 1916 das kurzlebige Regentschaftskönigreich Polen gegründet - ein vom Deutschen Reich und Österreich-Ungarn abhängiger Vasallenstaat noch ohne genau definierte Grenzen, die freilich erst nach Kriegsende festgelegt werden sollten. Die Zukunft eines polnischen Staates wurde von zahlreichen deutschen Publizisten, Historikern, Sozial- und Kulturwissenschaftlern, politischen Aktivisten oder Rechtsgelehrten wie etwa Max Weber, Georg Cleinow oder Conrad Bornhak - um nur einige zu nennen - eifrig diskutiert. ${ }^{22}$

19 Tazbir, Polska przedmurzem Europy, S. 161-176.

20 Vgl. Mitter, Armin; Das "Phantom» Polen - die "polnische Frage» in den Beziehungen zwischen den Teilungsmächten vom Ende der 1880er Jahre bis 1914, in: Fragmentierte Republik. Das politische Erbe der Teilungszeit in Polen 1918-1939 (Phantomgrenzen im östlichen Europa, Bd. 2), hrsg. von Michael G. Müller/Kai Struve, Göttingen 2017, S. 223 - 254.

21 Zitat nach Senn, Alfred Erich: The Entente and the Polish Question 1914-1916, in: Jahrbücher für Geschichte Osteuropas 25,1 (1977), S. 21-33, hier S. 21.

22 Bornhak, Conrad: Österreich und Polen, in: Die Grenzboten. Zeitschrift für Politik, Literatur und Kunst, vom 28.11.1917, S. 233-238; Cleinow, Georg: Die Polenpolitik der Deutschen und Polen, Die Grenzboten. Zeitschrift für Politik, Literatur und Kunst, vom 1.3.1918; ders.: Die Polenfrage vor der Ent- 
Die Staaten der Triple Entente, allen voran Russland, hielten hier selbstverständlich entschieden dagegen und versuchten, eigenen Einfluss auf die polnische Frage und die Polen zu nehmen. Relativ früh stellte Petrograd die Vereinigung aller polnischen Gebiete (nach der Eroberung der deutschen und österreichischungarischen Provinzen) unter der Ägide der Romanows in Aussicht. ${ }^{23}$ So wurde bereits nach Kriegsausbruch die "slawische» Waffenbruderschaft zwischen Russen und Polen beschworen. Ein geeintes Polen sei nur unter russischer Führung und dem "Zepter des russischen Kaisers» möglich, so der bereits am 14. August 1914 an die Polen gerichtete Aufruf des Großfürsten und Generals Nikolaj Nikolajevič, des Oberbefehlshabers der russischen Streitkräfte im ersten Kriegsjahr. Eine im gleichen Jahr veröffentlichte Postkarte, auf der sich ein polnischer und ein russischer Soldat über der besiegten Figur des deutschen Kaisers Wilhelm die Hände reichen, sollte diese Vorstellung untermauern (Abb. 2). ${ }^{24} \mathrm{Zu}$ propagandistischen Zwecken wurde dabei von den Russen auch das messianistische Bild Polens als eines heldenhaften Opfers freilich nur der deutschen Aggression bemüht. Stellvertretend mag hierfür die von dem russischen Grafiker und Maler Sergej Solomko gezeichnete und in Paris veröffentlichte allegorische Darstellung der geschundenen und gekreuzigten Polonia stehen (Abb. 3). ${ }^{25}$ Solomko war noch vor Kriegsausbruch nach Frankreich emigriert, nahm aber bis zum Ende des Russländischen Kaiserreichs zahlreiche Aufträge aus Petrograd an, die die Propagierung eines heldenhaften Bildes von Russland bei gleichzeitiger Denunzierung der Mittelmächte zum Ziel hatten. Publizistische Unterstützung fanden die russischen Polenpläne auch durch zahlreiche aus der russischen Hauptstadt heraus agierende russophile Polen. ${ }^{26}$

Auch in den Überlegungen der westlichen Demokratien kam der polnischen Frage mit Fortlauf des Krieges - vor allem aber nach den Erfolgen der Mittelmächte im Osten - eine immer größere Bedeutung zu. Ein auf Kosten der Mittelmächte restituierter polnischer Staat wurde als ein wichtiger potentieller Partner der Franzosen und Briten im Osten des Kontinents erachtet, der - angesichts der sich ab 1915 zusehends verschlimmernden militärischen wie auch innenpoliti-

scheidung, Berlin 1918. Zu Max Webers Überlegungen zur polnischen Frage während des Ersten Weltkriegs siehe Mommsen, Wolfgang J.: Max Weber und die deutsche Politik 1890-1920, Tübingen ${ }^{3} 2004$, S. $229-246$.

23 Siehe hierzu Toporowicz, Wieslawa: Sprawa polska w polityce rosyjskiej 1914-1917, Warszawa 1973.

24 Sowohl die Ansprache des Großfürsten Nikolaj als auch die Postkarte finden sich auf der dem Vorkriegswarschau gewidmeten Website Fundacja Warszawa 1939, online abrufbar unter: http://www.warszawa1939.pl/muzeum/84/pocztowka-propagandowa-z-listopada-1914-roku (01.04. 2021).

25 Solomko, Sergey: Pologne, ca. 1915, online abrufbar unter: https://commons.wikimedia.org/wiki/ File:Sergey_Solomko_025.JPG (01.04.2021).

26 Spustek, Irena: Polacy w Piotrogrodzie, 1914-1917, Warszawa 1966. 


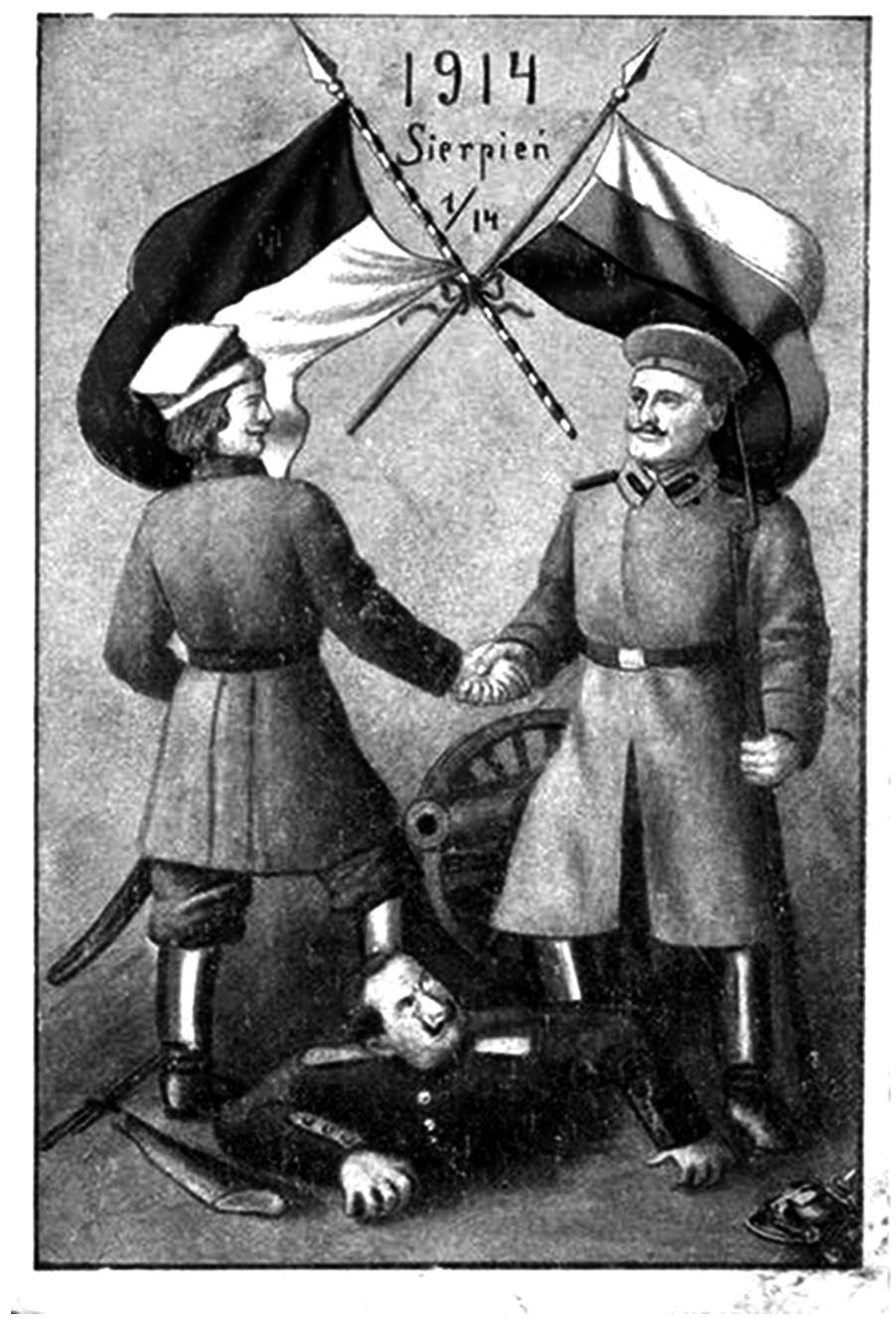

Abb. 2: Russische Propagandapostkarte vom November 1914. Wydawnicto Stef. Granke, Fundacja Warszawa 1939

schen Lage Russlands - die deutschen und österreichisch-ungarischen Truppen zusätzlich hätte binden und so zur Entlastung der Fronten in Flandern und Frankreich beitragen können. ${ }^{27}$ Sinnbildlich hierfür kann eine 1916 in großer

27 Bierzanek, Remigiusz: Państwo polskie w politycznych koncepcjach mocarstw zachodnich, 19171919 (Biblioteka ıSpraw miẽdzynarodowychı, Bd. 14), Warszawa 1964; Pajewski, Janusz: Wokół sprawy polskiej. Paryż-Lozanna-Londyn 1914 - 1918, Poznań 1970; Hovi, Kalervo: Cordon Sanitaire or Barrière de l'Est? The Emergence of the New French Eastern European Alliance Policy 1917-1919, Turku 1975; Ślad- 


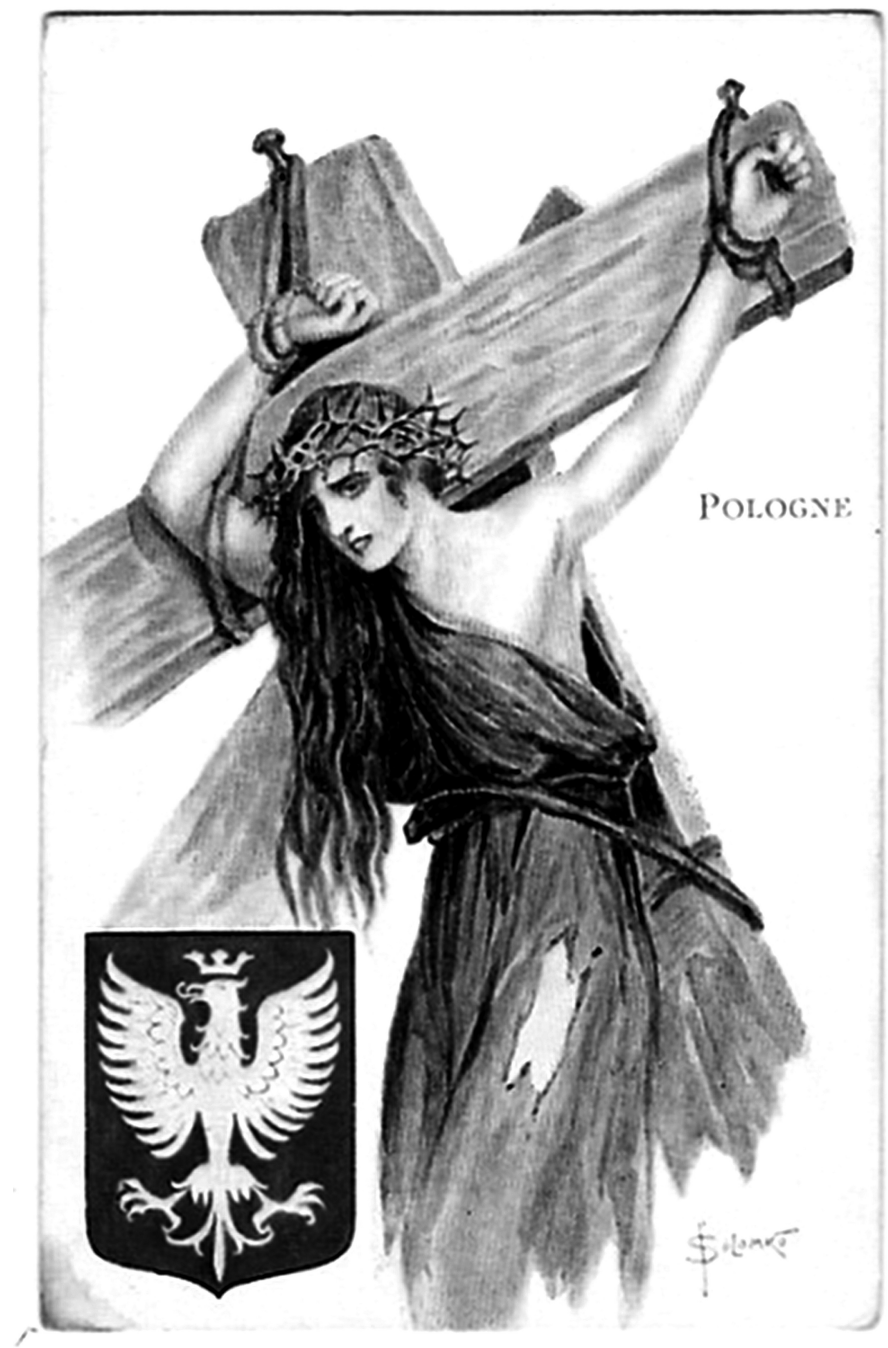

Abb. 3: Sergej Solomko, »Pologne», ca. 1915

Auflage in Paris publizierte Postkarte stehen, auf der vor dem Hintergrund einer (wenn auch umgedrehten) polnischen, weiß-roten Fahne Zitate solcher namhaften französischen Politikergrößen wie Louis Barthou, Adéodat Compère-Morel, Paul Henri Balluet d'Estournelles de Constant, Édouard Herriot und Charles Hum- 
bert standen, die die von Frankreich angestrebte Restitution des polnischen Staates versicherten. ${ }^{28}$

Die zunehmende Ausrichtung der polnischen Unabhängigkeitsaktivisten hin zur Entente - und hier vor allem zu Frankreich - führte 1917 zur Gründung des Polnischen Nationalkomitees (»Komitet Narodowy Polski«, KNP) in Paris. Letzteres sollte die polnischen Unabhängigkeitsbestrebungen vor den Westmächten vertreten. ${ }^{29}$ Seine Mitgliederliste liest sich mit Maurycy Zamoyski, Roman Dmowski, Ignacy Jan Paderewski, Erazm Piltz, Stanisław Kozicki, Jan Emanuel Rozwadowski, Konstanty Skirmunt, Franicszek Fronczak, Władysław Sobański, Marian Seyda oder Józeg Wielowieyski (um nur einige wenige zu nennen) wie ein Who-iswho der in den Westen emigrierten, politisch aktiven polnischen Diaspora. Das KNP sah sich als der offizielle Vertreter eines für die Zukunft - nach dem Sieg der Entente gegen die Mittelmächte - geplanten unabhängigen polnischen Staates und war unter anderem für die Entstehung wie die Organisation der polnischen Truppen in Frankreich, der sogenannten Blauen Armee unter dem französischen General Louis Archinard (ab Oktober 1918 unter Józef Haller), zuständig. Aus dem Umfeld des KNP beziehungsweise in seinem Auftrag wurden zahlreiche Schriften in französischer Sprache publiziert, die die Wiederherstellung eines souveränen polnischen Staates propagierten.

Auch in den Vereinigten Staaten wurde die polnische Diaspora aktiv und machte eifrig Werbung für einen unabhängigen polnischen Staat. Wie bereits in Frankreich und Großbritannien erachteten die polnischen Exilaktivisten den Ausbruch des Krieges zwischen den europäischen Mächten als die große Chance für die Wiederherstellung der Rzeczpospolita. Stellvertretend hierfür kann die Zeitschrift "Free Poland" stehen, die nicht zufällig gleich nach Kriegsbeginn vom September 1914 bis 1918 in Chicago als der Stadt mit der größten polnischen Minderheit in den Vereinigten Staaten zweiwöchentlich publiziert worden war. ${ }^{30}$ Herausgegeben von F. J. Medwecki, Karol Wachtel, Tomasz T. Lasecki, Franciszek

28 Vgl. die Ausstellung »Wem gehört Polen?« Propagandapostkarten aus dem Ersten Weltkrieg (»Do kogo należy Polska?« Propagandowe kartki pocztowe z czasów I wojny światowej), die unter der Leitung der Polnischen Akademie der Wissenschaften in Wien vom 22. Januar bis zum 11. Februar 2018 im Posener Residenzschloss ausgestellt stattgefunden hat. Siehe hierzu http://www.lepszypoznan. pl/2018/01/19/do-kogo-nalezy-polska.html (01.04.2021); »Drapeau de la Pologne», ca. 1916, Bibliothèque municipale de Lyon (Rés454732_002_0131), URL: https://numelyo.bm-lyon.fr/f_view/BML: BML_0401400101Res454732_002_0131(16.04.2021).

29 Vgl. Leczyk, Marian: Komitet Narodowy Polski a Ententa i Stany Zjednoczone, 1917-1919, Warszawa 1966.

30 Hierzu mit weiteren Verweisen Srodecki, Paul: Die polnische Minderheit in den USA und die Polenfrage zu Beginn des Ersten Weltkriegs im Spiegel der Emigrantenzeitschrift Free Poland, in: Erster Weltkrieg im östlichen Europa und die russischen Revolutionen 1917 (Schriften des Zentrums für Osteuropastudien [ZOS] der Universität Kiel, Bd. 9), hrsg. von Alexander Trunk u. Nazar Panych, Berlin u. a. 2019, S. $69-88$. 


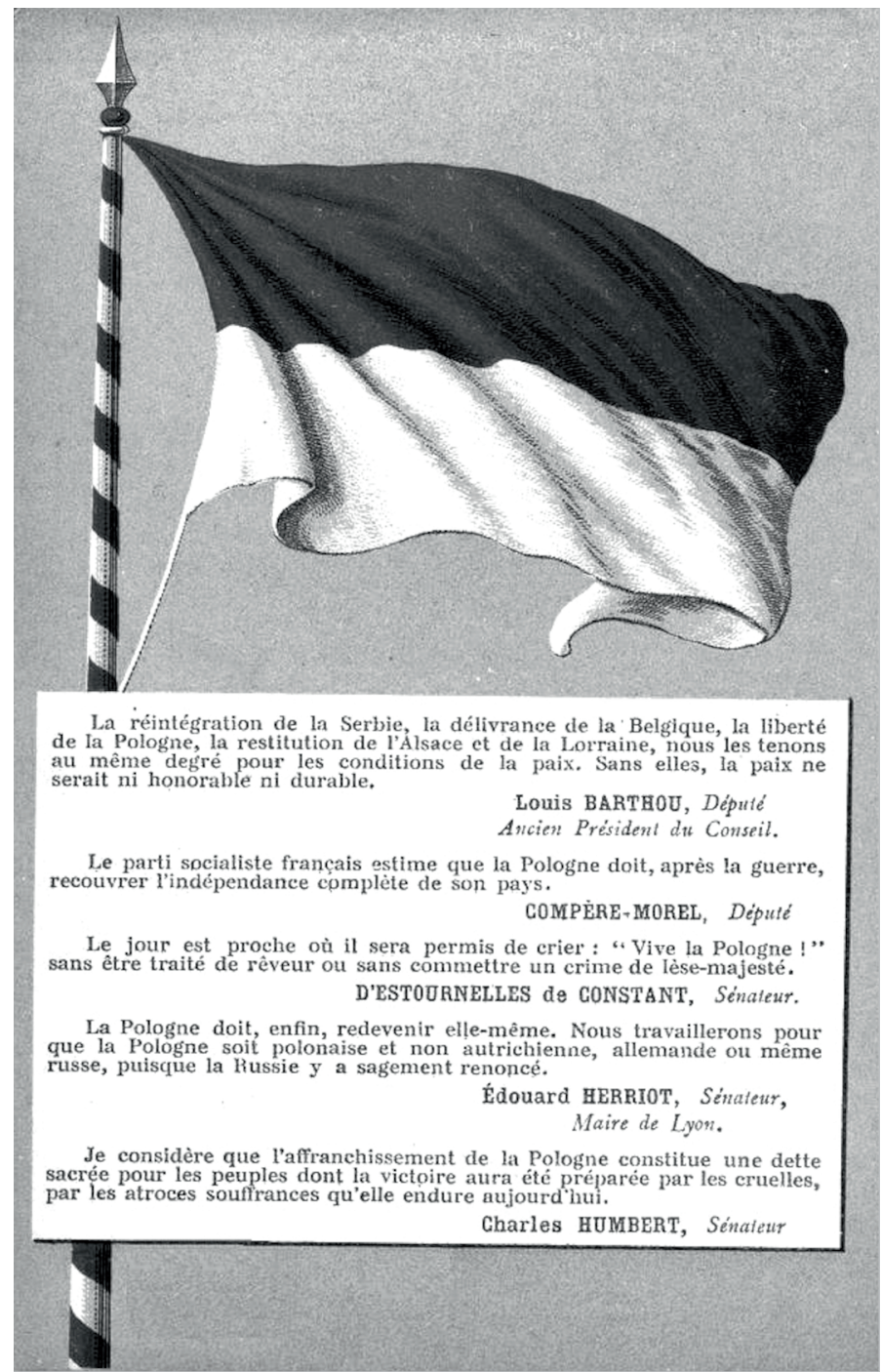

Abb. 4: "Drapeau de la Pologne», ca. 1916, Bibliothèque municipale de Lyon (Rés454732 002 0131)

S. Barc, Jan Skibiński, Feliks Ładon und Stanisław Osada vom Polish »National Council of America" stand der Untertitel des Blattes fast schon programmatisch für seine inhaltlichen Ziele, nämlich »die Wahrheit über Polen und seine Bevölkerung« (»The Truth About Poland and Her People») der US-amerikanischen Leserschaft näherzubringen. ${ }^{31}$ Der Polish National Council of America beschloss die

31 Free Poland. A Semi-Monthly. The Truth About Poland and Her People 1 (1914), 1, S. 1. 
Herausgabe der Zeitung bereits am 17. August 1914, also unmittelbar nach der Julikrise und dem Kriegsausbruch in Europa. ${ }^{32}$ Den Herausgebern des Blattes zufolge sollte ein unabhängiges Polen nicht nur die als historische Ungerechtigkeit empfundenen Teilungen des späten 18. Jahrhunderts wettmachen und den Polen einen eigenen Nationalstaat geben. Ein restituiertes Polen wurde auch als ein wichtiger Eckpfeiler einer europäischen Balance of Power der Nachkriegsordnung und somit als ein entscheidender Garant des Friedens erachtet:

»The world needs a free Poland. Humanity asks for it. Civilization calls for it. Universal peace is impossible without it. Justice demands it. The threefold crime, perpetrated by three powers more than a hundred years ago, is ineffaceable blot on the escutcheon of justice and before the court of civilization and humanity an everlasting reminder of unrepaired wrongs. Until restitution shall have been granted to the dismembered nation of its priceless freedom, any plan for a universal peace will be but a mirage, beautiful but nonexistent and unrealizable.«33

Seit den ersten Ausgaben kennzeichnete die zwei Mal monatlich erscheinende Zeitung ein starker antipreußischer Grundton, bei dem das Bild des preußischen Expansionismus und Militarismus immer wieder bemüht worden war. ${ }^{34}$ Doch auch Stimmen, die sich gegen Russland richteten, prägten das Weltbild der Zeitschrift. Stanisław Osadas im Oktober 1914 veröffentlichter Essay »Why Poles Distrust Russia» kann hierbei exemplarisch für das Misstrauen stehen, das von großen Teilen der polnischen Eliten, und zwar nicht nur der sich im Exil befindenden, Petrograd entgegengebracht wurde. ${ }^{35}$ Ähnlich wie bei den in den jeweiligen Teilungsgebieten wirkenden Unabhängigkeitsaktivisten schieden sich an der Rolle Russlands einerseits und Deutschlands andererseits bei der Wiedererrichtung eines polnischen Staates die Geister. Gerade in der Anfangsphase des Krieges wurde der weitverbreiteten Russlandskepsis insbesondere von der polnischen Exilpublizistik mit dem Hinweis auf die vom Deutschen Reich ausgehende Gefahr begegnet. Helena Piotrkowska sah in ihrer Abhandlung »The Polish Question« beispielsweise Deutschland als den gefährlichsten Gegner polnischer Unabhängigkeitsbestrebungen - und nicht etwa Russland mit "all seinem Verrat und seiner primitiven Brutalität». Sie führte aus: „With all her treachery and primitive brutality Russia has never been so dangerous to the Poles as Germany. The higher civilization of the latter made her not more humane, but more efficient as a jailer. ${ }^{36}$ Diese Vorstellung wurde auch von Antoni Karabasz geteilt, der offen Par-

Ebd., S. 2.

Ebd, S. 4.

Lasecki, T.T.: Mr. Churchill on the Terms of Peace, in: Free Poland 1 (1914), 2, S. 3 - 4.

Osada, S.: Why Poles Distrust Russia, in: Free Poland 1 (1914), 2, S. 12 - 13.

Piotrkowska, H.: The Polish Question, in: Free Poland 1 (1914), 3, S. 10 -13, hier S. 13. 
tei für Russland und seine Alliierten Frankreich und Großbritannien ergriff. Hinter all den leidvollen Erfahrungen, die den Polen seit den Teilungen des späten 18. Jahrhunderts und dem Verlust der Eigenstaatlichkeit widerfahren seien, stünde Deutschland, oder besser ein vom preußischen Militarismus vereinnahmtes Deutschland, das im Laufe der Zeit intrigenhaft mit seiner antipolnischen Politik auch Russland infiltriert habe:

"It is true that the Russians have proved criminal in their relation to Poland, but their crimes have been those of the barbarian, while Prussia has been boasting of her supreme culture and accentuating it with unspeakable atrocities. The Prussians have met with universal condemnation, and the world at large expects them to go down in defeat. That is the reason the Poles should take sides with Russia, France and England in their efforts to destroy the militarism of Prussia. [...] Instinctively Poland feels that it is not the Russians that are the greatest enemy of her interests. It was Prussia that spread throughout the $19^{\text {th }}$ century its baneful influence on the politics of Russia. It was Prussia that kept Russia from granting home rule to Poland. «7 $^{37}$

Die sich überstürzenden Ereignisse auf dem östlichen Kriegsschauplatz - angefangen mit den siegreichen Kampagnen der Mittelmächte der Jahre 1915 und 1916 und dem hiermit einhergehenden Vorstoß deutscher und österreichisch-ungarischer Truppen weit nach Osteuropa hinein, allem voran aber nach dem Ausbruch der Russischen Revolutionen 1917, dem Sturz der Romanowmonarchie und dem Ausscheiden Sowjetrusslands aus dem Ersten Weltkrieg durch den Friedensvertrag von Brest-Litowsk vom 3. März $1918^{38}$ - rückten die russischen Pläne eines Königreichs Polen von Petrograds Gnaden in weite Ferne. Das alles hatte freilich auch Auswirkungen auf die polnische Unabhängigkeitsbewegung und ihre Beurteilung der Rolle eines restituierten souveränen polnischen Staates: So verschoben die Oktoberrevolution, der Ausbruch des Russischen Bürgerkriegs und der sich langsam abzeichnende Sieg der Bolschewiken die Argumentationsmuster in den Schriften der polnischen Publizisten und Unabhängigkeitsaktivisten wieder Richtung Osten. Alte Topoi, die insbesondere die messianistische Rolle Polens und des polnischen Volkes als wichtigstes Bollwerk gegen vermeintliche oder auch tatsächliche Gefahren aus dem Osten seit dem späten Mittelalter bemühten, wurden reaktiviert und in die Unabhängigkeitspropaganda der nationalkatholischen Eliten involviert. So veröffentlichten in dieser Zeit beispielsweise Publizisten wie etwa der römisch-katholische Priester Nikodem Cieszyński oder der His-

37 Karabasz, A.: Poland - The Mary Stuart of Nations, in: Free Poland 1 (1914), 4, S. 4-6, hier S. 5. 38 Vgl. Hildermeier, Manfred: Russische Revolution. Voraussetzungen, Februarrevolution, Roter Oktober, Sozialistische Revolution, Sowjet, Räteverfassung, Köpfe der Revolution, Bürgerkrieg, Nationale Frage, Kulturelle Revolution, Interpretationen (Fischer-Taschenbücher, Bd. 15352), Frankfurt a. M. 2004; Haumann, Heiko (Hrsg.): Die Russische Revolution 1917 (UTB, Bd. 2950), Köln/ Weimar/ Wien 2007; Schirmer, J.: "Weder Krieg noch Frieden" - das diplomatische Dilemma von Brest-Litowsk 1917/18, in: Journal der juristischen Zeitgeschichte 5,1 (2011), S. 9-13. 
toriker Kazimierz Konarski mehrere Essays über die Rolle Polens als Vormauer gegen den Osten, sprich gegen das zaristische Russland bzw. - nach 1917/18 gegen die neue "revolutionäre» Gefahr der Bolschewiken. ${ }^{39}$ Bereits 1914/15 hatte Władysław Smoleński in seiner Abhandlung "Naród polski w walce o byt" (»Die polnische Nation in ihrem Kampf um das Dasein«), die allerdings erst 1919 publiziert wurde, an Polens besondere geopolitische Lage zwischen seinen überaus aggressiv agierenden Nachbarn Deutschland und Russland und an seine zahlreichen Kriege gegen letztere erinnert. Durch diese aufopfernde Rolle an der östlichen Flanke Europas habe Polen, indem es die russische Despotie lange genug vor einem Einfall in den Westen aufgehalten habe, erst die Entfaltung der europäischen Kultur und Zivilisation ermöglicht. ${ }^{40}$

Wie oben bereits erwähnt verbanden Smoleński wie auch zahlreiche weitere polnische politische Publizisten mit einem in den ersten Kriegsjahren freilich noch ungewissen Sieg der Entente, und zwar explizit Frankreichs und Großbritanniens, größte Hoffnungen auf die Wiederherstellung eines unabhängigen polnischen Staates. ${ }^{41}$ Es verwundert somit nicht, dass Smoleński seine oben aufgeführte Schrift unter dem Pseudonym Władysław Grabieński im Jahre 1916 in Paris in einer leicht modifizierten Fassung als "La Pologne. Resumé d'histoire» drucken ließ, um so für die Wiederherstellung eines polnischen Staates im Westen Werbung zu machen. ${ }^{42}$ Ein ähnliches, Polens Verdienste bei der Abwehr der Tataren, Osmanen oder Moskowiter hervorhebendes Werk war Marceli Handelsmanns 1918 in Paris und Lausanne erschienenes "La Pologne, son histoire, son organisation et sa vie». Handelsmann unterstrich neben dem Bollwerksstatus Polens auch die entscheidende Mitwirkung der Polen bei der Ausbreitung der lateinischen Christenheit nach Osten im Mittelalter und der Frühen Neuzeit. ${ }^{43}$

\section{Eine neue Gefahr aus dem Osten}

Auf diese Muster griff die nationalkatholische Rechte nach der Wiedererlangung der Souveränität im November 1918 gern zurück. Vor allem im Zuge der Pariser Friedenskonferenz 1919, die schließlich im Friedensvertrag von Versailles münden sollte, erschienen zahlreiche Pamphlete und Aufsätze, die Polens Anrecht auf einen souveränen Staat unterstrichen und auf seine Bedeutung als Bollwerk ge-

39 Tazbir, Polska przedmurzem Europy, S. 170 f.

40 Smoleński, Władysław: Naród polski w walce o byt. Zarys historyczny, Warszawa 1919.

41 Vgl. Senn, The Entente.

42 Smoleński, Władysław: La Pologne. Resumé d'histoire, Paris 1916.

43 Handelsmann, Marceli: La Pologne, son histoire, son organisation et sa vie, Paris u. Lausanne 1918. 
gen Deutschland und Russland hinwiesen. Eines der am weitesten verbreiteten Werke dieser Art war Jan Tarnowskis "La Pologne rempart de la civilisation«, in dem letzterer offen das bereits im frühen 19. Jahrhundert durch Adam Jerzy Czartoryski angedachte und in der Zwischenkriegszeit vor allem von Józef Piłsudski favorisierte Intermarium-Konzept propagierte - die Idee also von einem polnischen Staat, der von der Ostsee bis zum Schwarzen Meer reichen sollte. Seiner Meinung nach konnte Polen nur unter diesen territorialen Voraussetzungen als Europas Bollwerk gegen Deutschland und Russland fungieren. ${ }^{44}$ Ähnliches lässt sich auch in den Schriften des Historikers Władysław Konopczyński vernehmen. ${ }^{45}$

Der restituierte polnische Staat sollte - so der Grundton in den meisten der im Umfeld der Versailler Friedenskonferenz publizierten Schriften - in seiner außenpolitischen Ausrichtung sehr eng an die Westmächte angebunden werden. Das erklärt auch, weswegen ein Großteil der Pamphlete in französischer Sprache publiziert worden ist. In diese reiht sich auch Stanisław E. H. Filasiewicz' 1920 herausgegebene Quellensammlung »La question polonaise pendant la guerre mondiale» ein, die zahlreiche während des Ersten Weltkrieges erschienene internationale Dokumente zur polnischen Frage versammelt. ${ }^{46}$ Filasiewicz, ein aus Teschen stammender Architekt, gehörte während des Ersten Weltkrieges zahlreichen polnischen Organisationen in der Schweiz an und schloss sich 1919 dem Polnischen Nationalkomitee (KNP) in Paris an. Für die meisten Mitglieder des KNP stand die Erlangung der staatlichen Souveränität an oberster Stelle, die Grenzen eines wiederhergestellten unabhängigen polnischen Staates sollten hingegen erst danach ausgehandelt werden.

So war für den ebenfalls zum KNP gehörenden Unabhängigkeitsaktivisten Jan Emanuel Rozwadowski mit der Restitution des polnischen Staates der Krieg freilich noch längst nicht beendet, wie er im Vorwort der oben aufgeführten Dokumentensammlung festhielt:

"Cette renaissance, reconnue par le traité de Versailles [...] ne marqua pour la Pologne ni la fin de la guerre, ni la fixation de ses frontières. C'est en soutenant une guerre des plus dures que la République ressucitée doit se constituer et forger son avenir.«47

44 Tarnowski, Jan: La Pologne rempart de la civilisation, o.O. 1919.

45 So z. B. in Konopczyński, Władysław: Obrona kultury zachodniej, in: Polska w kulturze powszechnej, Bd. 1, hrsg. von Feliks Koneczny, Kraków 1918, S. 32 - 51.

46 Filasiewicz, Stanislas: La question polonaise pendant la guerre mondiale (Recueil des Actes diplomatiques, Traités et Documents concernant la Pologne, Bd. 2), Paris 1920.

47 Rozwadowski, Jan Emanuel: Avant-propos, in: La question polonaise pendant la guerre mondiale (Recueil des Actes diplomatiques, Traités et Documents concernant la Pologne, Bd. 2), hrsg. von Stanislas Filasiewicz, Paris 1920, VII-VIII, hier: VII. 
Vielmehr würde an den östlichen Grenzen Polens, dieses »Bollwerks Europas», ein Kampf ausgefochten, in dem - quasi als Fortsetzung des Ersten Weltkrieges über die Existenz der westlichen Welt entschieden werde:

"A cette époque la Pologne parvient enfin à pouvoir combattre pour sa propre liberté et pour la civilisation occidentale. Liant sa destinée aux destinées de ses grands alliés, elle s'empresse de leur payer sa dette de reconnaissance en redevenant le srempart de l'Europer. $1^{48}$

Dieses Bild wurde auch von nichtpolnischen, zumeist französischen Publizisten im Jahre der großen Friedenskonferenz adaptiert. So rühmte Georges Bienaimé die Polen wegen ihrer Freiheits- und Gerechtigkeitsliebe, weswegen sie in der Vergangenheit schon als die Franzosen des Nordens bezeichnet worden seien. Seit dem Mittelalter sei Polen ein Bollwerk Europas gegen die Bedrohungen aus dem Osten - hier vor allem gegen die Tataren und Osmanen - gewesen. ${ }^{49}$ Charakteristisch und, bedenkt man den nationalen Ursprung des Verfassers, wenig überraschend ist jedoch, was Bienaimé als den größten Verdienst Polens erachtete. So habe das Land in allererster Linie über Jahrhunderte die "Ausbreitung des Deutschtums« aufgehalten. Im ersten Kapitel der Abhandlung »Les grands événements de l'Histoire de Pologne» beleuchtet Bienaimé sechs große Eigenheiten der polnischen Geschichte, die seiner Meinung nach essentiell für das Verständnis der sogenannten polnischen Frage seien. Bezeichnenderweise schreibt er dem nach Osten gerichteten Expansionsdrang der "germanischen Rasse» den ersten Rang in seiner Aufzählung zu und sieht im diesem die Triebfeder für die Formierung der westslawischen Reiche Böhmen und Polen im frühen Mittelalter, die angesichts des gemeinsamen "germanischen" Feindes aus dem "Chaos der slawischen Völker« entstanden seien. ${ }^{50}$ Eine Union zwischen beiden Ländern war schon immer ein Dorn im Auge der deutschen Nachbarn gewesen, sei sie doch geradezu dafür prädestiniert, dem »dreiste[n] Deutschtum in seinem Drang nach Osten« Einhalt zu gebieten. ${ }^{51}$

Einem kriegstreiberischen, militaristischen, expansionistischen und antisemitischen Deutschen Reich wurde hierbei ein freiheitsliebendes und in seinem Wesen

\footnotetext{
48 Ebd., VIII.

49 Bienaimé, Georges: Ce qu'il faut savoir de la Question Polonaise, Paris 1919, S. 5: »Le peuple de Pologne aimait la liberté et la justice; il était affable, bienveillant, chevalerseque; on l'appelait le `Français du Nordı. Pendant des siècles il avait été le rampart de l'Europe contre l'invasion tatare et la conquête turque."

50 Ebd., S. 6: „Quand se forma l'Etat polonais (965), la race germanique fixée entre le Rhin et l'Elbe, avait déjà dépassé ce fleuve vers l'Est et attaint l'Oder. [...] C'est alors que du chaos des peoples slaves, sortirent deux royaumes chrêtiens, la Bohême et la Pologne."

51 Ebd.: "L'union de la Bohême et de la Pologne, des Tchèques et des Polonais, ces deux peuples frères pouvait arrêter le germanisme audacieux dans son Drang nach Osten; la politique germanique travailla toujours contre cette union.»
} 
demokratisch ausgerichtetes Polen gegenübergestellt, das als Verbündeter der westlichen Demokratien einen Gegenpol zu den autoritären Deutschen und Russen im Osten des europäischen Kontinents bilden sollte. Adam Skierko stilisierte in seinem Pamphlet "Les Juifs et La Question Polonaise» Polen gar zu einem Hort der Toleranz, böte es doch im Gegensatz zum antisemitischen Deutschland allen Juden einen Zufluchtsort. ${ }^{52}$ In dem Kapitel "Antisemitisme des Allemands et tolerance des Polonais» beschreibt er den seit der Ausrufung des Deutschen Reiches 1870/71 in Deutschland gestiegenen Antisemitismus und stellt diesem als Gegenspiegel die vermeintliche polnische Toleranz und Semitophilie gegenüber.

Insbesondere nach dem für Polen siegreichen polnisch-sowjetischen Krieg der Jahre 1919 bis 1921 wurde an die Rolle der Polonia als Verteidigerin Europas vor dem Bolschewismus erinnert, etwa von dem Philosophen und Publizisten Wincenty Lutosławski, der 1922 schrieb:

»Europa braucht für seine gesellschaftliche Entwicklung und seine Sicherheit vor Asien einen Staat, der es von Asien abgrenzt. Moskau kann dieser Staat nicht sein, da es selbst asiatisch ist. Dieser Staat als Schutzwacht Europas war Polen und Polen sollte es auch bleiben. [...] Europa braucht eine lebendige Mauer, eine freie Rzeczpospolita, die sie vor dem Osten beschützen würde. Das ist Polens Daseinsberechtigung - seine Mission. «53

Der Historiosoph Feliks Koneczny war noch radikaler in seinen Ausführungen als er in seinem vielzitierten Werk "Polskie Logos a Ethos. Roztrzasania o znaczeniu i celu Polski» (»Polens Logos und Ethos. Reflektionen zur Bedeutung und zur Zielsetzung Polens«) offen zu einer kompletten Trennung der westlichen von der östlichen Welt aufrief. Letztere sah er als dem Westen in allen Belangen - vor allem aber auf der kulturell-zivilisatorischen Ebene - unterlegen an. Das Vermischen beider Kulturkreise könne nur in einer Katastrophe für die mehr entwickelte, sprich westliche Zivilisation enden. Koneczny zufolge sei somit die 1596 zwischen der römisch-katholischen Kirche und den orthodoxen Bischöfen des polnisch-litauischen Verbundsstaates geschlossene Kirchenunion von Brest einer der größten Fehler polnischer Geschichte gewesen, hätten doch die Kompromisse mit den

52 Skierko, Adam: Les Juifs et La Question Polonaise, Paris 1919.

53 Lutosławski, Wincenty: Praca narodowa. Program polityki polskiej, Wilno 1922, S. 189-190: »Europa dla swego rozwoju społecznego, dla swego bezpieczeństwa przed Azja potrzebuje państwa, któreby ją od Azji odgraniczało. Państwem tem Moskwa być nie może, gdyż sama jest azjatycką. Państwem tem na straży Europy stojącem była Polska, i Polska niem powinna pozostać. [...] Europa potrzebuje żywego muru, wolnej Rzeczypospolitej, coby ją broniła od Wschodu. To jest racja bytu Polski - jej misja." Vgl. Jaworski, Wit: Eleuteryzm i mesjanizm. U źródeł filozofii społecznej Wincentego Lutosławskiego (Biblioteka końca wieku), Kraków 1994; Jadacki, J. J.: Wincenty Lutosławski. Rozdział z dziejów myśli polskiej, in: Lutosławscy w kulturze polskiej, hrsg. von B. Klukowski, Drozdowo: 1998, S. 54 -87; Łukomski, Grzegorz: Stereotyp najeźdźcy w czasie wojny polsko-bolszewickiej 1918-1920, in: Swoi i obcy [Eigene und Fremde] (Kultura polityczna w Polsce, Bd. 4,1), Bd. 1, hrsg. von Marceli Kosman, Poznań 2004, S. 161173; Tazbir, Polska przedmurzem Europy, S. 179. 
orthodoxen Untertanen nur zur Aufweichung der Rzeczpospolita und umgekehrt zur Stärkung Moskaus geführt:

"Wenn es die Union von Brest, wenn es dieses unglückliche Streben nach einer Synthese des Westens mit dem Osten in der Kirche nicht gegeben hätte, dann hätte die römischkatholische Hierarchie bereits im 18. Jahrhundert bis zum Ural gereicht und die westliche Zivilisation hätte in Russland gewonnen. ${ }^{54}$

Ganz im Sinne eines Wincent Lutosławski sah Koneczny Polens Existenzberechtigung in seiner exponierten geopolitischen Lage als Bollwerk der westlichen Welt gegen einen vermeintlich wilden und höchst aggressiven Osten:

„Unser geschichtliches Verhältnis zu Europa wurde bereits vor langer Zeit mit dem Beinamen `Vormauerı bedacht. Wir tragen die Schwere des Wachpostens zur Verteidigung der westlichen Zivilisation. [...] Unser Kampf mit Russland war und ist und wird immer und unveränderlich ein Kampf um die Zivilisation, um die Verteidigung der lateinischen Zivilisation sein. [...] Sogar in Polens schlimmsten Zeiten hat letzteres [...] die Vormauer Europas gegen das östliche Barbarentum gebildet. ${ }^{55}$

Die politischen Umbrüche in Russland im Zuge der Oktoberrevolution ließen die polnischen Nationalisten in ihren russophoben Ausführungen unbeeindruckt. Ganz im Gegenteil, mit dem Wechsel von einem negativ konnotierten schismatisch-asiatisch geprägten Despoten, zu einem weltlich geprägten, kommunistischen Arbeiterstaat schienen sich alle pejorativen, jahrhundertealten Russlandbilder für die polnische Rechte mit ihren starken nationalkatholischen Neigungen zu bestätigen: Die schismatischen Pseudo-Christen Russlands würden nun ihr wahres Gesicht zeigen und sich öffentlich zu ihrem ungläubigen, genuin atheistischen Wesen bekennen. So waren es vor allem nationalistisch gesinnte Kreise rund um die katholische Kirche in Polen, die in den Jahren 1919 bis 1939 geschlossen als eine wichtige Trägerschicht der gegen die Sowjetunion gerichteten Bollwerksrhetorik auftraten. ${ }^{56}$ Der politisch sehr aktive Priester Stanisław Ciążyń-

54 Koneczny, Feliks: Polskie Logos a Ethos. Rozstrzasania o znaczeniu i celu Polski, Bd. 2, Poznań/ Warszawa 1921, S. 23: „Gdyby nie unia brzeska, gdyby nie owo niefortunne dażenie do syntezy Zachodu i Wschodu w Kościele, hierarchia rzymskokatolicka sięgałaby już od XVIII wieku po Ural i cywilizacja zachodnia byłaby w Rosji zwyciężyła.»

55 Ebd., S. 82 u. 85: „Stosunek nasz dziejowy do Europy określono już dawno przydomkiem "przedmurza». Stoimy na ciężkim posterunku w obronie cywilizacji zachodniej. [...] Walka nasza z Rosją była i jest, i zawsze i niezmiennie walka o cywilizację, walka w obronie cywilizacji łacińskiej. [...] Nawet w najgorszych dla Polski czasach stanowiła ona [...] przedmurze dla Europy od barbarzyństwa wschodniego."

56 Mysłek, Wieslaw: Przedmurze. Szkice z dziejów Kościoła katolickiego w II Rzeczypospolitej, Warszawa 1987; Caumanns, Ute: Die polnischen Jesuiten, der Przegląd powszechny und der politische Katholizismus in der Zweiten Republik. Ein Beitrag zur Geschichte der katholischen Presse Polens zwischen den Weltkriegen (1918 - 1939) (Veröffentlichungen der Forschungsstelle Ostmitteleuropa, Bd. 55), Dortmund 1996; dies.: Soviet Russia vs. Nazi-Germany. Poland's Big Neighbours from the Viewpoint of the Polish Jesuits (1918-1939), in: Churches in the Century of the Totalitarian Systems, hrsg. Von Jerzy Kłoczowski/ W. Lenarczyk/ S. Łukasiewicz, Lublin 2001, S. 83 - 90. 
ski etwa verknüpfte in einem 1920 innerhalb der Zeitschrift »Przewodnik Katolicki« publizierten Memorandum die einstige Rolle Polens als Vorposten der abendländischen Christenheit gegen den schismatischen und heidnischen Osten mit der neuen, noch gefährlicheren Aufgabe angesichts der russischen Revolution und des polnisch-sowjetischen Krieges. Jetzt, da an Europas östlicher Flanke mit der Machtübernahme der Bolschewiken die größte Bedrohung seiner Geschichte entstanden sei, sei auch Polens Stellenwert innerhalb des europäischen Kulturkreises bedeutender als je zuvor:

"Und so steht Polen, kaum, dass es sich aus dem Grabe erhoben habe, heute wieder vor seiner historischen Aufgabe, so als wolle Gott uns zeigen, dass wir dem Pfad unserer Ahnen, der Verteidiger des Glaubens und der Freiheit, folgen sollten. Was ist denn nun eigentlich unser Kampf gegen den Bolschewismus? Es ist der Kampf zur Verteidigung der Christenheit und der westlichen Zivilisation, so wie bereits einst vor Jahrhunderten, als wir die heidnischen Wilden aus dem Osten abwehrten. So wie einst, so haben wir es auch heute mit der Barbarei zu tun, die unser Land verwüstet, es niederbrennt, plündert oder Menschenraub begeht, indem sie gewaltsam die Männer in die Rote Armee zwingt und die Frauen vergewaltigt. «57

Eingebettet wurde diese antibolschewistische Rhetorik in ältere Vormauertopoi. So sei Ciążyński zufolge die von den Sowjets ausgehende Gefahr eine neue Form der seit Jahrhunderten in regelmäßigen Abständen auftretenden alten Bedrohung aus dem unzivilisierten Osten, die - in neue Gewänder gehüllt - sich wieder gegen den vermeintlich höher entwickelten Westen wende. Diesmal sei sie aber viel gefährlicher als in der Vergangenheit, machten sie doch der ideologische Unterbau des Kommunismus gepaart mit den neuen Mitteln der industrialisierten Kriegsführung zum größten Feind der christlichen Welt:

"Es ist dieselbe Barbarei wie die der Tataren vergangener Jahrhunderte, nur, dass sie um ein Vielfaches gefährlicher ist, bedient sie sich doch der neuesten technischen Mittel. Sie ist auch um ein Vielfaches verderblicher, will sie doch in ihren Zielsetzungen bewusst den Sturz der christlichen Zivilisation herbeiführen. [...] Die Welle der Barbarei schlägt somit gegen die polnische Vormauer - letztere muss aber bestehen bleiben und die Schläge aushalten, denn Polen ist heute wie bereits vor Jahrhunderten der Schutzwall Europas, der Schutzwall der Christenheit. ${ }^{58}$

57 Ciążyński, Stanisław: Przedmurze Chrześcijaństwa, in: Przewodnik Katolicki 26,35 (1920), S. 356 357, hier S. 357: "I oto dziś, zaledwie Polska z grobu się podniosła, stanęło przed nią natychnmiast jej zadanie dziejowe, jak gdyby Pan Bóg chciał nam pokazać, że kroczyć powinniśmy droga naszych przodków, obrońców wiary i wolności. Czemże jest bowiem walka nasza z bolszewizmem? Jest to walka w obronie chrześcijaństwa i cywilizacji zachodniej, jak przed setkami lat, gdy odpieraliśmy pogańską dzicz wschodu. Jak ongi, tak i dzisiaj mamy do czynienia z barbarzyństwem, które pustoszy kraj, pali, rabuje, uprowadza w jasyr, wcielając mężczyzn do armji czerwonej, znęcając się nad kobietami.»

58 Ebd.: "Taka sama dzicz, jak Tatarzy minionych wieków, tym niebezpieczniejsza, że zaopatrzona w nowoczesne środki techniczne, tym gorsza że dążaca świadomie w swoich kierownikach do obalenia cywilizacji na gruncie chrześcijańskim powstałej. [...] Fala barbarzyństwa bije o przedmurze polskie, a ono musi stać, musi wytrzymać ciosy, bo Polska dziś, jak przed wiekami, jest szańcem Europy, szańcem chrześcijaństwa.» 
An die Domino-Effekt-Theorie anknüpfend unterstrich Ciążyński Polens Bedeutung für Europa und malte ein düsteres Bild vom Niedergang der ganzen westlichen Welt, sollte der polnische Vorposten den Bolschewiken unterliegen:

"Und so sind auch heute die Augen der ganzen Welt auf uns gerichtet: Erweist sich Polen als standhaft in seinem Widerstand oder unterliegt es [den Bolschewiken]? Französische Schriften erinnern an unsere lobenswerte Stellung als Vormauer der Christenheit und stellen fest, dass wir diese Zuschreibung nie mehr verdient gehabt hätten als heute, sei doch das Schicksal des Westens heute von unserer Ausdauer abhängig. Und das ist keine Übertreibung. Sollte nämlich der polnische Wall zerspringen und die Bolschewiken sich mit den verbrecherische Pläne schmiedenden Deutschen verbünden, so würde nicht nur Polen fallen, sondern auch die Freiheit Europas. ${ }^{59}$

Ähnliche Bilder von dem polnisch-sowjetischen Krieg wurden auch von höheren Kreisen des polnischen Klerus propagiert. In einem Schreiben an Papst Benedikt XV. rühmte etwa der polnische Episkopat die Glanzleistung polnischer Truppen in der Verteidigung der römischen Kirche wie auch der ganzen Christenheit und bat den Pontifex - ähnlich wie bereits in den mittelalterlich-frühneuzeitlichen Suppliken angesichts der Türken- und Moskowitergefahr - um diplomatische Unterstützung im Kampf gegen Sowjetrussland:

»Heiliger Vater! Unser Vaterland kämpft nun seit zwei Jahren gegen den Feind des christlichen Kreuzes, die Bolschewiken. Das wiederauferstandene Polen, das durch den vierjährigen Kampf fremder Mächte auf seinem Boden mehr als erschöpft ist, das durch den jetzigen Krieg am Boden zerstört liegt, steht nun vor seinem finalen Kampf. Wenn Polen dem bolschewistischen Einfall unterliegt, wird die ganze Welt dem Untergang geweiht sein, denn eine neue Flut wird sie überschwemmen, eine Flut von Mördern, eine Flut des Hasses, der Feuersbrunst und der Entweihung des Heiligen Kreuzes. Heiliger Vater, in diesem schwierigen Moment bitten wir Dich um seelische wie diplomatische Unterstützung. Bete für uns, sodass wir nicht besiegt werden und - mit Gottes Hilfe - dass wir mit unseren Körpern eine Mauer zum Schutze der Welt vor der schrecklichsten Gefahr bilden." ${ }^{60}$

Benedikt griff diese Rhetorik willentlich auf. In einem Schreiben an den Kardinalvikar Basilio Pompilj etwa bezeichnete der Papst den Krieg Polens gegen Sowjetrussland als einen Kampf nicht nur um die eigene staatliche Existenz, sondern

59 Ebd., S. 357: „I dziś oczy całego świata skierowane sa na nas: Czy Polska wykaże dość odporności, czy nie ulegnie? Pisma francuskie przypominają naszą godność Przedmurza Chrześcijaństwa i stwierdzają, że nigdy może bardziej niż dziś na tę nazwę nie zasłużyliśmy, bo losy Zachodu dziś od naszej wytrwałości zależą. Niema w tem przesady. Gdyby tama polska pękła i bolszewicy połączyli się z knującemi zbrodnicze plany Niemcami, zginęłaby nietylko Polska, lecz i wolność Europy."

60 Zitiert nach Wysocki, W. J.: Kościół Polski wobec najazdu bolszewickiego w 1920 roku, in: W nieustannej trosce o polska diasporę. Tom studiów historycznych i politologicznych dedykowany Księdzu Arcybiskupowi Szczepanowi Wesołemu, hrsg. von R. Nir/ M. Szczerbiński/ K. Wasilewski, Gorzów Wielkopolski 2012, S. 81-96, hier S. 82: „Ojcze Święty! Ojczyzna nasza od dwóch lat walczy z wrogiem Krzyża Chrystusowego, z bolszewikami. Odradzajaca się Polska, wyczerpana czteroletnimi zmaganiami się ościennych państw na jej ziemiach, wyniszczona obecną wojną, zdobywa się na ostatecznz wysiłek. Jeżeli Polska ulegnie nawale bolszewickiej, klęska grozi całemu światu, nowy potop ją zaleje, potop mordów, nienawiści, pożogi, bezczeszenia Krzyża." 
vielmehr als eine aufopfernde und entscheidende Auseinandersetzung zum Erhalt der christlichen Welt. Die Bolschewiken beschrieb Benedikt hierbei als gottlose Usurpatoren, als eine neue Plage aus dem Osten, die jedoch blutrünstiger und gefährlicher sei als alle zuvor dagewesenen. Hiermit knüpfte der Pontifex - ob bewusst oder unbewusst - auf das bereits in den Jahrhunderten zuvor mit der Bollwerksrhetorik immer wieder vermengte "plaga orientalis«-Bild an. Polen als "baluardo dell`Europa» müsse seinem historischen Auftrag nachkommen und die bolschewistischen Armeen aufhalten. ${ }^{61}$

Das Bild des restituierten Polens als des wichtigsten Bollwerks Europas gegen die Bolschewiken wurde auch in zahlreichen Propagandapostern bemüht. ${ }^{2}$ Die verwendeten Motive sind recht verschieden, reichen hierbei - in Anlehnung an Figuren aus der christlichen Mythologie wie dem Erzengel Michael der dem heiligen Georg - von der allegorischen Stilisierung der polnischen Armee zum drachenbezwingenden Heros, der einer dreiköpfigen roten Hydra als Sinnbild für den Bolschewismus die Stirn bietet, über den Abwehrkampf eines mit einem Schild bewaffneten polnischen Soldaten gegen mehrere Bajonette, bis hin zu polnischen Soldaten, die aufopferungsbereit einen Palisadenzaun, der von skelettartigen, Bolschewikenfahnen tragenden Massen bestürmt wird, am Zusammenbrechen hindern (Abb. 5-7). ${ }^{63}$ So unterschiedlich sie auch in ihrem Setting sind, sie allesamt vereinigen wie bereits die zuvor vorgestellten literarischen Werke zwei

61 Benedikt XV.: "Con vivo compiacimento", in: https://w2.vatican.va/content/benedict-xv/it/letters/ 1920/documents/hf_ben-xv_let_19200 805_vivo-compiacimento.html (01.04.2021): "Quando tutte le Nazioni civili si inchinavano silenziose dinanzi alla prevalenza della forza sul diritto, la Santa Sede fu sola a protestare contro la iniqua spartizione della Polonia e contro la non meno iniqua oppressione del popolo polacco. Ma ora vi è molto di più; ora non solo è in pericolo la esistenza nazionale della Polonia, ma tutta l'Europa è minacciata dagli orrori di nuove guerre. Quindi non è soltanto l'amore verso la Polonia, ma è l'amore verso tutta l'Europa che Ci muove a desiderare che i fedeli tutti si uniscano a Noi nel supplicare l'Altissimo affinché per intercessione della Vergine Santissima, protettrice della Polonia, voglia risparmiata al popolo polacco questa suprema sciagura, e nello stesso tempo voglia allontanare questo nuovo flagello dalla dissanguata Europa."Vgl. hierzu Wiadomości Archidyecezyalne Warszawskie 10,9-10 (1920), S. 185.

62 Vgl. Szczotka, S.: Wizerunek bolszewika w polskich plakatach propagandowych z wojny polskorosyjskiej 1919-1920 ze zbiorów Muzeum Niepodległości w Warszawie, in: Niepodległość i Pamięć 19,1-4 (2012), S. 205 - 213; Paduszek, Konrad: Działalność propagandowa służb informacyjno-wywiadowczych Wojska Polskiego w czasie wojny polsko-bolszewickiej 1919-1921. Organizacje, metody, treści, Toruń 2004.

63 J. P.: DO BRONI. WSTE|cPUJCIE DO ARMJI OCHOTNICZEJ!, o.J. 1920, Muzeum Niepodległości w Warszawie, Nr. inw. MN-Pl.2042; Manon [Pseudonym eines anonymen Grafikers], DO BRONI. RATUJMY OJCZYZNE|c! PAMIE|cTAJMY DOBRZE O NASZYM PRZYSZŁYM LOSIE, Lwów 1920; Bartłomiejczyk, E.: NA POMOC! WSZYSTKO DLA FRONTU! WSZYSCY NA FRONT!, Warszawa 1920. Vgl. Gạsiorowska, A.: Poland first to fight. Katalog polskiego plakatu wojskowego, Warszawa 2002, S. 38, 47 u. S. 55. [Abb. 5: J. P., "Zu den Waffen. Tretet der Freiwilligenarmee bei!«, URL: http://www.muzeumwp. pl/emwpaedia/plakat-do-broni-wstepujcie-do-armii-ochotniczej.php (16.04.2021).] [Abb. 6: Manon, "Zu den Waffen. Lasst uns die Heimat retten! Lasst uns unser zukünftiges Schicksal nicht vergessen!«, Lwów 1920, URL: https :// 1920.gov.pl/plakat/do-broni-ratujmyojczyzne-pamietajmy-dobrze-o-naszym-przyszlym-losie/

(16.04.2021).] [Abb. 7: Edmund Bartłomiejczyk, "Zu Hilfe! Alles für die Front! Alle an die Front!«, Warszawa 1920. URL: http://www.muzeumwp.pl/emwpaedia/plakat-na-pomoc-wszystko-dla-frontuwszyscy-nafront.php (16.04.2021).] 


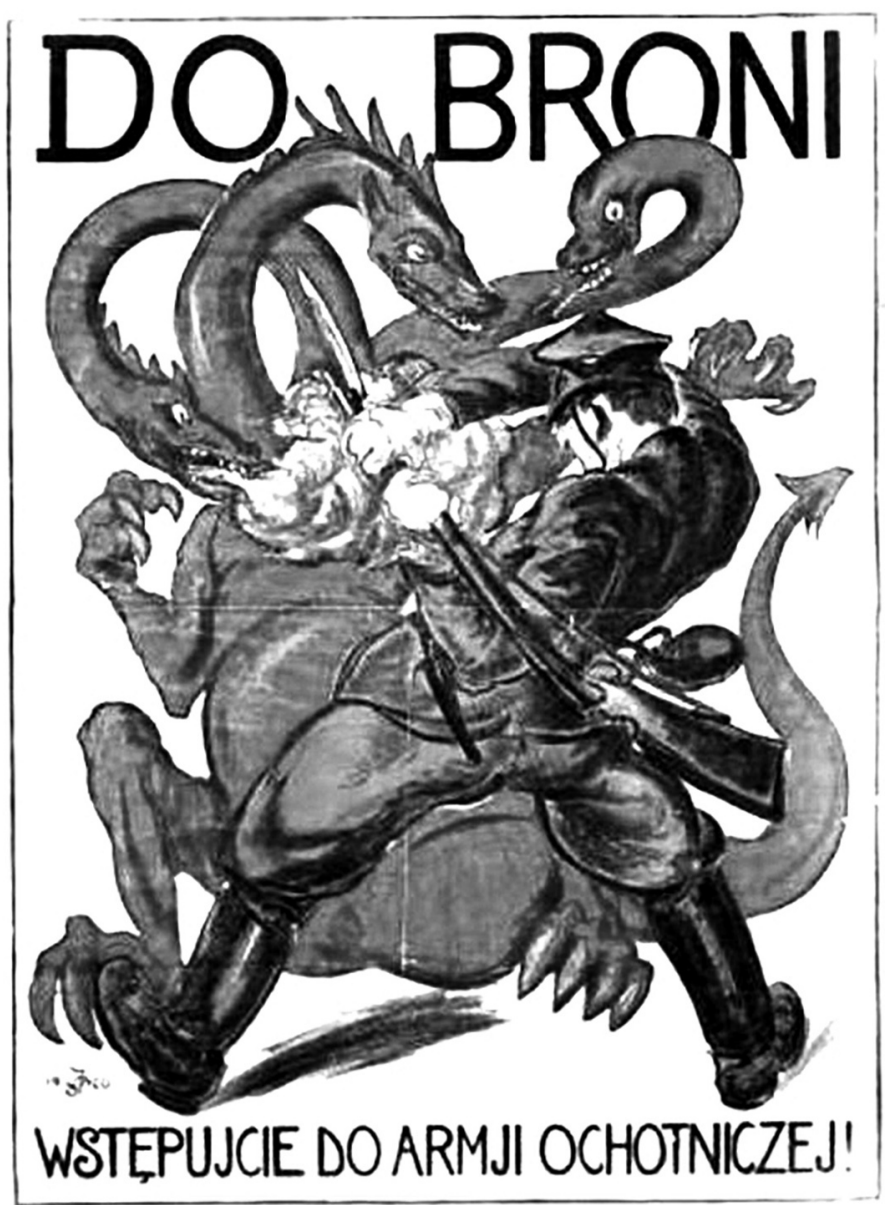

Abb. 5: J. P., "Zu den Waffen. Tretet der Freiwilligenarmee bei!»

in der polnischen Erinnerungskultur weit verbreitete Narrative, die auch in den Propagandapostern zu einem Bild verschmelzen: Den Topos des märtyrerhaften, messiasgleichen polnischen Bollwerks, das die "Barbaren» des Ostens am Durchbruch gen Westen aufhält.

Das polnische Bollwerksbild bis zum Ende der Zweiten Rzeczpospolita

Nach dem Sieg über Sowjetrussland in der Schlacht bei Warschau im August 1920 wurde die Bollwerksallegorie zu einem omnipräsenten Topos der antisowjetischen Rhetorik. In dem Nachrichtenblatt der Erzdiözese Warschau gratulierte 


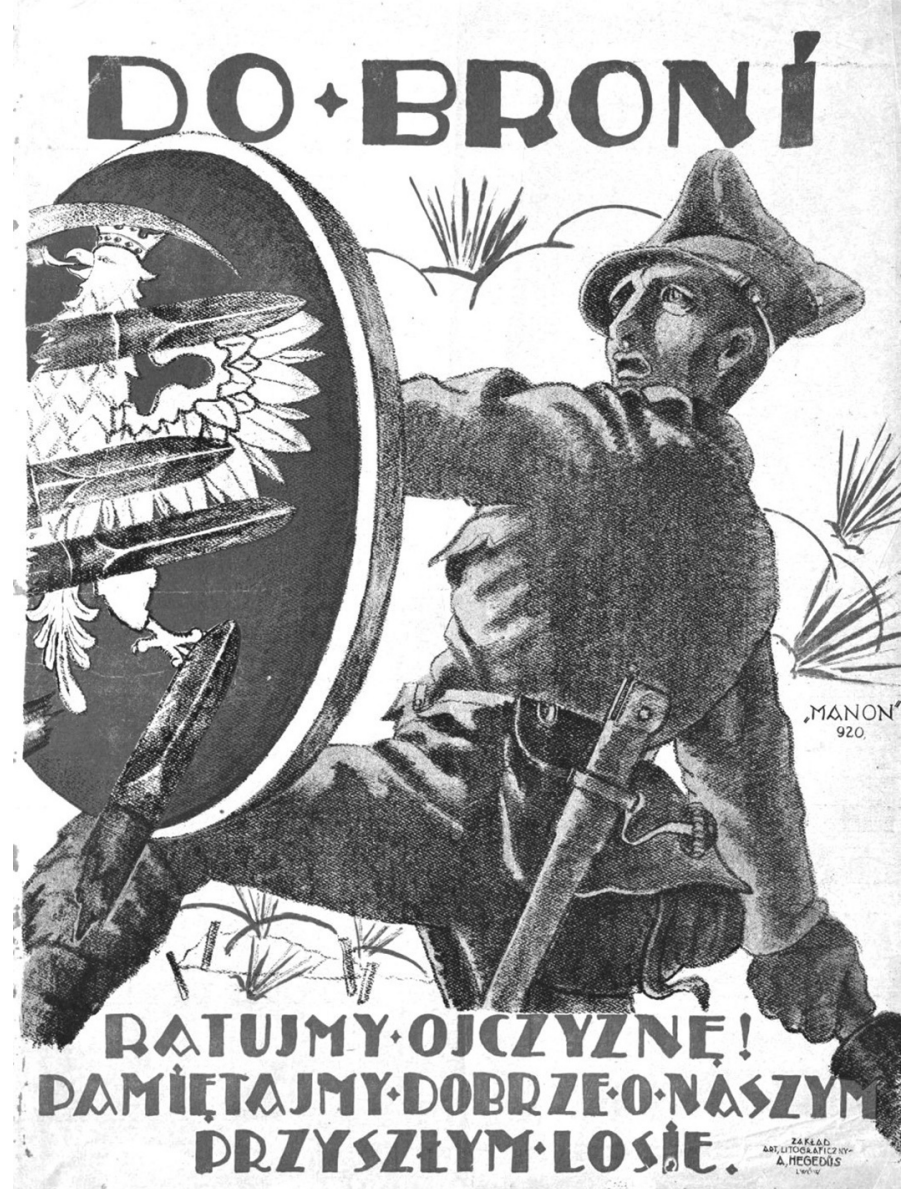

Abb. 6: Manon, "Zu den Waffen. Lasst uns die Heimat retten! Lasst uns unser zukünftiges Schicksal nicht vergessen!«, Lwów 1920

man den polnischen Truppen und ihrem Befehlshaber Józef Piłsudski zum erfolgreichen Bezwingen des sowjetischen Eindringlings und zu der gelungenen Bestätigung der alten militärischen Tradition Polens, wonach es das Bollwerk der Christenheit und der Verteidiger der westlichen Kultur sei "Vormauer zu sein», das sei auch im 20. Jahrhundert Polens Aufgabe, konstatierte 1927 der katholische Priester und Chefredakteur des vom Jesuitenorden herausgegebenen »Przeglacd Powszechny«, Jan Urban. Ähnliche Artikel erschienen in der von dem Franziskanerorden ab 1935 herausgegebenen Zeitschrift "Mały Dziennik», in deren Rahmen insbesondere der später von der römisch-katholischen Kirche heiliggesprochene Maksymilian Kolbe mehrere antibolschewistische wie auch antisemitische und mit Bollwerksallegorien durchzogene Essays publizierte. Überhaupt wurden - 


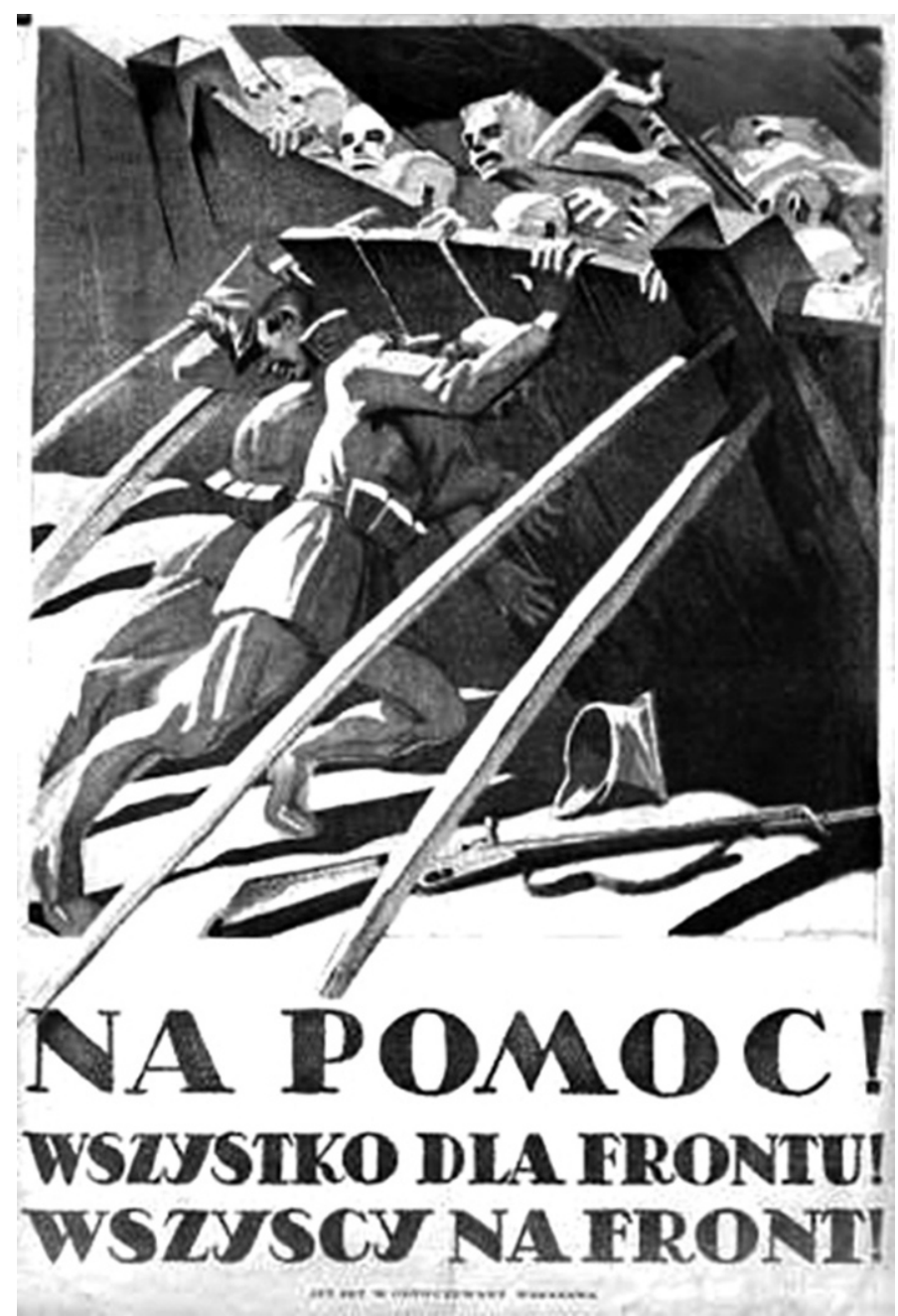

Abb. 7: Edmund Bartłomiejczyk, »Zu Hilfe! Alles für die Front! Alle an die Front!», Warszawa 1920.

ähnlich wie etwa bei den Nationalsozialisten in Deutschland - in Polen der Zwischenkriegszeit antikommunistische nur zu gern mit antisemitischen Elementen vermengt. Der römisch-katholische Priester Marian Wiśniewski beispielsweise zeigte vollstes Verständnis für das harte Vorgehen Hitlerdeutschlands gegen die Juden nach der Machtübernahme 1933. Die antijüdischen Maßnahmen der Nationalsozialisten seien in Wiśniewskis Augen nichts Anderes als eine Art notwendige Selbstverteidigung gegen die "jüdische Pest« gewesen. Ein tatkräftiges Einschreiten gegen den "östlichen Judeo-Bolschewismus", der seinen Anfang in der verwerflichen Revolution von 1917 genommen habe, bedeute schließlich die euro- 
päische Christenheit zu verteidigen. Dies sei ein Handeln, das keineswegs von den Christen verurteilt werden dürfe, wie Wiśniewski in der Zeitschrift "Pro Christo» im Juli 1934 schrieb.

Die Ostpolitik der sogenannten Zweiten Rzeczpospolita wie auch die Herausbildung ihrer östlichen Grenzen in den Jahren unmittelbar nach dem Ende des Ersten Weltkrieges konzentrierten sich in der ideologischen Ausrichtung rund um zwei Lager: Roman Dmowski und Józef Piłsudski. Anders als Roman Dmowski, der den Hauptgegner eines unabhängigen Polens im Deutschen Reich sah, bildete für Piłsudski Russland bzw. Sowjetrussland und ab 1922 die Sowjetunion die größte Gefahr für den Fortbestand eines neuerrichteten polnischen Staates. Für letzteren konnte ein unabhängiges Polen nicht zeitgleich mit einem starken Russland als Nachbarn existieren. Bereits 1904 proklamierte Piłsudski in einem Memorandum, dass das Hauptziel eines wieder unabhängigen Polens »die Zerschlagung des russischen Staates in seine Hauptbestandteile und die Unabhängigkeitsmachung der durch Gewalt in das Imperium eingegliederten Länder« sei. ${ }^{64}$

Die Vernichtung bzw. schrittweise Zerstückelung Russlands wurde zum tragenden Motto der von Piłsudski initiierten Prometheismus-Bewegung, die sich nach der Niederlage der Weißen im Russischen Bürgerkrieg hauptsächlich der Eindämmung des geopolitischen Einflussausbaus der Sowjetunion richtete. Durch die Unterstützung separatistischer Bewegungen auf dem Gebiet der Sowjetunion sollte die streckenweise Demontage des Vielvölkerstaates vorangetrieben werden, der ab 1918 mehrere ostmittel- und osteuropäische Länder annektiert hatte. Unterstützt wurden von Polen aus speziell Unabhängigkeitsbestrebungen in der Ukraine, Weißrussland, Karelien, dem Baltikum, dem Kaukasus und Zentralasien. Ergänzend zur Konzeption des Prometheismus bestand das Projekt einer hauptsächlich polnisch geführten Konföderation in Mittel- und Osteuropa namens Intermarium. Der Prometheismus war unter anderem aus dem Streben nach vollständiger Wiedererlangung staatlicher Unabhängigkeit aller slawischen Völker und dem Widerstand gegen die Ausweitung der Einflusssphäre der Sowjetunion in den Westen entstanden. Des Weiteren galt er als eine der Leitlinien für die polnische Außenpolitik zwischen 1918 und 1939. Im September 1921 unterstrich Piłsudski nochmals seine genuin antirussische Haltung: „Wir Polen wollen es nicht wahrhaben, dass für uns Russland - welches auch immer - immer eine 
Konkurrenz darstellen wird. Wir begegnen stets dem Hindernis Russland - Russland als reale Macht, Russland als ein lebendiger Begriff auf dieser Welt. «65

Antisowjetische bzw. antikommunistische Presse und Bücher, die die Russische Revolution wie auch den sowjetischen Staat aus einer rein negativen Perspektive beschrieben, hatten im Polen der Zwischenkriegszeit Konjunktur. 1927 erschien gar eine offen gegen den Kommunismus und vor allem die Sowjetunion gerichtete Zeitschrift. Bereits der Titel des monatlich in Warschau erscheinenden und von Henryk Glass herausgegebenen Blattes war Programm: Er lautete „Bój z bolszewizmem. Wszechstronny informator antykomunistyczny" (1927-1931) also «Kampf dem Bolschewismus. Ein umfassendes antikommunistisches Informationsblatt». 1937 folgte mit "Prawda o komunizmie - Biuletyn Informacyjny» (»Die Wahrheit über den Kommunismus - ein Informationsbulletin«) ein weiteres von Henryk Glass herausgegebenes antikommunistisches Monatsblatt.

\section{Fazit}

Die polnischen Unabhängigkeitsaktivisten schöpften bei ihren Schriften, die während des Ersten Weltkrieges und in den Jahren unmittelbar nach 1918 die Forderung nach einem souveränen polnischen Staat unterstreichen sollten, aus einem Sammelsurium altbewährter nationaler Topoi, von denen insbesondere das Bollwerksmotiv wie auch das messianistische Bild von Polen als dem leidgeplagten "Christus der Völker« zweifelsohne zu den am häufigsten bemühten gehörten. Dabei wurde die exponierte geopolitische Lage zwischen zwei mächtigen Nachbarn geschickt in die Argumentationen eingebunden: Polen als der Vorposten (west)europäischer Libertät sei stets von einem militaristisch-expansionistischen Deutschland einerseits und einem autoritär-despotischen Russland andererseits bedroht und letzten Endes auch aufgeteilt worden. Ein unabhängiger polnischer Staat sei also, so die Botschaft in den meisten der hier vorgestellten Schriften, nicht nur die Wiedergutmachung des geschichtlichen Unrechts der Teilungen. Vielmehr könne das restituierte Polen wie schon einst die frühneuzeitliche Rzeczpospolita sowohl Deutschland als auch Russland in Schach halten und somit den Westen (vor allem Deutschland) entlasten.

65 Garlicki, A./ Świętek, R. (Hrsg.): Dariusz 1919-1935, Warszawa 1992, S. 98. Vgl. Wyszczelski, Rozpruwanie, S. 6; Nowak, Andrzej: Reborn Poland or Reconstructed Empire? Questions on the Course and Results of Polish Eastern Policy (1918-1921), in: Lithuanian Historical Studies 13,1 (2008), S. 127150 . 
Besonders auffällig ist dabei die Uneinigkeit der polnischen Publizisten darüber, welche Rolle Deutschland wie auch Russland bei der Lösung der polnischen Frage zugeschrieben werden sollte und wie denn beiden nach einer zukünftigen Unabhängigkeitserlangung außenpolitisch entgegenzutreten sei. Eine Minderheit plädierte - sicherlich noch einem direkten Hinwirken der jeweiligen Teilungsmächte ausgesetzt - hier zu Kriegsbeginn für die deutschen beziehungsweise russischen Polenpläne. Die Mehrheit der polnischen Unabhängigkeitsaktivisten sah jedoch sowohl in Deutschland als auch in Russland die größten Gegner eines restituierten souveränen polnischen Staates. Bis 1917, dem Jahr der Russischen Revolutionen also, hielt der Großteil der polnischen Publizistik - abgesehen von den deutschlandnahen und dem kurzlebigen Regentschaftskönigreich zugeneigten Befürwortern einer Zusammenarbeit mit Berlin - noch Deutschland für den Hauptantagonisten der polnischen Unabhängigkeitsbestrebungen. Es mehrten sich - wie weiter oben mehrfach aufgeführt - Darstellungen, die Polen zu einem slawischen Bollwerk der Freiheit gegen den preußisch-germanischen Militarismus und Imperialismus stilisierten. Russland kam in diesen propagandistischen Abhandlungen ein wenig besser weg und wurde in seinem Wirken als Teilungsmacht nur zu oft auf den Rang eines durch die skrupellosen Intrigen Berlins gegen die Polen manipulierten Instruments deutscher Außenpolitik herabgesetzt. Davon eine russlandneutrale oder gar russlandfreundliche Einstellung abzuleiten, ginge aber entschieden zu weit. Vielmehr wurden beide, Deutschland und Russland, als Feinde Polens dargestellt; nur dass eben ersteres als gefährlicher, da vermeintlich entwickelter und organisierter, eingestuft wurde, während letzterem der altbewährte Topos des barbarischen und chaotischen Ostens zugeschrieben wurde.

Der Zusammenbruch der Mittelmächte 1918 und die aus polnischer Sicht beunruhigenden Ereignisse im Osten des europäischen Kontinents ließen zunehmend das bolschewistische Russland als größte Bedrohung eines unabhängigen polnischen Staates erscheinen. Von besonderem Interesse ist hierbei, mit welchem Eifer die bereits im 19. Jahrhundert immer wieder bemühten Bollwerkstopoi und messianistischen Polenbilder während des Ersten Weltkrieges, insbesondere aber in den letzten zwei Kriegsjahren und im Zuge des polnisch-sowjetischen Krieges 1919 bis 1921 verbreitet wurden. Hier dienten beide Narrative, die in der Vorstellung Polens als einer aufopferungsbereiten Vormauer Europas beziehungsweise einem das europäische Hinterland verteidigenden Christus der westlichen Völker ihre Verschmelzung fanden, der polnischen nationalen Bewegung als willkommene propagandistische Instrumente zur Festigung und Legitimierung der eigenen nationalen Identität. Sie fungierten in diesen ungewissen Jahren der Staatsbildung den (überwiegend nationalkatholischen) polnischen Eliten als ein wichtiger 
integrativer Orientierungsanker des Kollektivgedächtnisses, der dem eigenen Land sowohl nach innen als auch nach außen die Europäizität zuschrieb. Gerade vor dem Hintergrund der bolschewistischen Bedrohung wurde hierbei Europa auch als Anlehnung an ältere, bis in die heutige Zeit in weiten Bevölkerungsteilen Polens bekannte "Antemurale«-Topoi der Vormoderne - als ein in sich abgeschlossener christlicher Kulturkreis verstanden, den es vor dem "unchristlichen" Bolschewismus zu beschützen galt. Beiden Topoi kam innerhalb der polnischen Unabhängigkeitspublizistik große Bedeutung im Bereich der politischen Agitation zu. In geradezu pathetischen Worten beschworen die Publizisten den aufopferungsvollen Kampf vergangener Generationen gegen äußere Bedrohungen und verbanden diesen mit eigenem Kampf um einen unabhängigen polnischen Staat.

Dass das Bild Polens als Beschützer des christlichen Europas auch ein Jahrhundert nach dem Ende des Ersten Weltkrieges an seiner Wirkungskraft unter den nationalkatholischen Eliten des Landes nichts eingebüßt hat, zeigten die Feierlichkeiten zum 99. Jahrestag der polnischen Unabhängigkeitserlangung und die mit reichlich Pathos aufgeladene Ansprache des Vorsitzenden der Partei »Prawo i Sprawiedliwość» (PiS, »Recht und Gerechtigkeit») Jarosław Kaczyński im November 2017. Letzterer erinnerte an die Ereignisse des Herbstes 1918 wie auch die schwierige geopolitische Lage der Zweiten Rzeczpospolita zwischen Sowjetrussland (bzw. der Sowjetunion) und Deutschland und verband diese mit den Realitäten der heutigen Republik Polen, die wie bereits vor hundert Jahren die Mission eines christlichen Vorpostens zu erfüllen habe. Fast schon an die Huntington'sche "Clash of Civilizations«-Rhetorik anknüpfend beschwor Kaczyński hierbei einen Kampf, an dessen Ende ein auf europäischen Werten aufgebautes Europa den Sieg davon tragen müsse und bei dem einen im Inneren geeinten (sprich: nationalkatholisch ausgerichteten) Polen eine entscheidende Rolle zukommen sollte:

„Polen war innerhalb dieser 99 Jahre [seit 1918, Hervorhebung d. V.] 50 Jahre seiner Unabhängigkeit beraubt. Es war ein Opfer zweier schrecklicher Totalitarismen geworden des deutschen und des russischen. Und die Folgen dieser Unfreiheit des 20. Jahrhunderts, wie auch die Folgen der früheren [Unfreiheit, gemeint ist die Zeit der Teilungen, Hervorhebung d. V.], dauern bis heute an. [...] Das Jahr zum Gedenken des hundertsten Jahrestags wird ein enorm wichtiges sein, in dem wir alles dafür tun sollten, damit so viele wie möglich der immer noch unvernarbten Wunden aufhören, unvernarbt zu sein. Damit die polnische Geistigkeit, der polnische Geist gestärkt werden, damit sich unsere Gemeinschaft stärkt, damit sich unsere Unabhängigkeit stärkt. [...] Wir müssen zeigen, dass diejenigen, die vor einhundert Jahren es geschafft haben, Gedanken mit Taten zu verbinden, nicht die letzte Generation sind, die es konnten. Wir müssen auch so eine Generation sein! [...] Aber das ist der einzige Weg, damit diese Jahrestage nicht nur bloße Feierlichkeiten sind, damit sie nicht nur bloße Augenblicke, sondern Schritte zu solch einem Polen hin sind, von dem wir alle träumen. [Einem Polen], das uns allen aber auch den Kindern und den Enkeln dieser Generation Sicherheit, Wohlstand, Stärke, Würde und das Gefühl garantieren wird, ein Pole zu sein, bedeute was Wichtiges zu sein. Es bedeute, jemand zu sein, der in Europa was bedeutet. Es bedeute vielmehr, jemand zu sein, der dem 
heutigen, kranken Europa den Weg zur Heilung, den Weg zur Rückkehr zu den fundamentalen Werten aufzeigt. Den Weg zur Rückkehr zur wahren Freiheit, den Weg zum Sieg und zur Stärkung unserer auf dem Christentum basierenden Zivilisation. Polen hat solch eine Chance! Nutzen wir sie!«66

66 Kaczyński, J.: Rede vor dem Józef Piłsudksi-Denkmal in Warschau vom 10.11.2017, entnommen aus dem Videoarchiv des Fernsehsenders TVP Info, online zugänglich unter: http://www.tvp.info/34771 308/jaroslaw-kaczynski-w-stulecie-odzyskania-niepodleglosci-rany-powinny-sie-zabliznic $\quad$ (01.04.2021): »Polska w ciagu tych 99 lat przez 50 była niepodległości pozbawiana. Padła ofiara dwóch straszliwych totalitaryzmów - niemieckiego i rosyjskiego. I skutki tej XX-wiecznej niewoli, tak jak i skutki tej dawnej [zaborów], trwają po dziś dzień. Trwaja w sferze materialnej, [...] ale przede wszystkim trwaja ciagle w sferze duchowej, w sferze świadomości. [...] Rok obchodów setnej rocznicy, to będzie rok ogromnie ważny, [...] w którym powinniśmy uczynić wszystko, by jak najwięcej tych ciągle niezabliźnionych ran przestało być niezabliźnionymi, by polska duchowość, by polski duch się wzmacniał, by wzmacniała się nasza wspólnota, by wzmacniała się nasza niepodległość. [...] Musimy pokazać, że ci, którzy sto lat temu potrafili połaczyć myśli i czyny, nie są ostatnim pokoleniem, którę to potrafiło. My też musimy być takim pokoleniem! [...] Ale to jest jedyna droga [...] ku temu, by te rocznice nie były tylko uroczystościami, nie były tylko momentami a były krokami ku takiej Polsce o której wszyscy mażymy. Która będzie nam wszystkim a także dzieciom i wnukom tego pokolenia zapewniała bezpieczeństwo, dobrobyt, siłę, godność i poczucie, że być Polakiem, to znaczy być kimś ważnym. To znaczy być kimś, kto w Europie znaczy. Co więcej, to znaczy być kimś, kto wyznacza dzisiejszej, chorej Europie drogę do uzdrowienia, drogę do powrotu do fundamentalnych wartości. Drogę do powrotu do prawdziwej wolności, drogę do zwycięstwa i umocnienia naszej opartej o chrześcijaństwo cywilizacji. Polska ma taką szansę! Wykożystajmy ją!« 